\title{
Description of four new species of Mesocletodes Sars, 1909 (Copepoda, Harpacticoida, Argestidae) and redescription of Mesocletodes robustus Por, 1965 from the South Atlantic, including remarks on the Mesocletodes abyssicola- group*
}

\section{LENA MENZEL ${ }^{\#} \&$ KAI HORST GEORGE}

Abt. DZMB, Forschungsinstitut Senckenberg, Südstrand 44, D-26382 Wilhelmshaven, Germany

${ }^{\#}$ Corresponding author: lmenzel@senckenberg.de

* In: Brökeland, W. \& George, K.H. (eds) (2009) Deep-sea taxonomy — a contribution to our knowledge of biodiversity. Zootaxa, 2096, 1-488.

\begin{abstract}
The present paper focuses on taxonomic and phylogenetic investigations of the family Argestidae Por, 1986. Samples, collected during the cruise DIVA 1 (M48/1) to the Angola Basin on board of RV "Meteor" (2000), contain amongst others several specimens belonging to the Mesocletodes abyssicola-group (Harpacticoida, Argestidae) which includes ten species so far. This paper deals with the description of Mesocletodes angolaensis sp. nov., M. bicornis sp. nov., M. dorsiprocessus sp. nov. and M. meteorensis sp. nov. as well as the redescription of Mesocletodes robustus Por, 1965. The four new species bear cuticular processes on the cephalothorax and/or telson, as is characteristic for the Mesocletodes abyssicola-group. These processes are supposed to be of high phylogenetic value, since they do not occur in any other taxon within the Argestidae, and are always inserted at the same position. Therefore, the Mesocletodes abyssicola-group is herein considered monophyletic.
\end{abstract}

Key words: deep sea, Angola Basin, DIVA, taxonomy

\section{Introduction}

Members of Argestidae Por, 1986 are free-living Harpacticoida with a worldwide distribution, mostly found in muddy sediments (Lang 1948; Sars 1909). Although they are one of the most abundant taxa in deep-sea localities, some argestid species have also been collected from shallow waters (Lang 1948; Por 1979; Sars 1909). Thus, Argestidae can be regarded as a typical, but not an exclusive deep-sea taxon (George 2004; Hicks \& Coull 1983; Huys \& Conroy-Dalton 1997; Noodt 1971). Their high abundance, high species richness and worldwide distribution make them highly suitable for phylogenetic, biogeographical and chorological investigations at the species level. Furthermore, due to clearly detectable diagnostic characters, they are easy to recognise in meiofauna samples. Therefore, Argestidae may constitute an adequate representative even for generalized meiobenthic deep-sea research.

To date, the genus Mesocletodes contains 32 species (Wells 2007) [Boxshall \& Halsey (2004) erroneously mention only 29 species], 10 of which are pooled in the Mesocletodes abyssicola-group due to the presence of cuticular processes on the cephalothorax and telson (Becker 1972; Bodin 1997; Lang 1936b; Sars 1921; Schriever 1985; Scott T. \& A. 1901). The remaining 22 species lack such processes and are therefore united in the Mesocletodes inermis-group (Bodin 1997).

The aim of the current (ongoing) investigation is, to shed some light on the phylogenetic status of the Mesocletodes abyssicola-group. The present publication includes remarks on whether the cuticular processes 
on the cephalothorax and telson, which have been traditionally used as diagnostic characters, are synapomorphies for the Mesocletodes abyssicola-group.

The samples from the Angola Basin also contained specimens of a known species, Mesocletodes robustus Por, 1965. This species is redescribed in the present publication.

\section{Material and methods}

Sediment samples were taken using a multicorer and an epibenthic sledge during the cruise DIVA 1 (M48/1) to the Angola Basin from July, $6^{\text {th }}$ to August, $2^{\text {nd }} 2000$, on board the RV "Meteor" (Kröncke \& Türkay 2003; Martínez Arbizu \& Schminke 2005) (Fig. 1). For methodology and treatment of the samples see Rose et al. (2005). The material was mounted into separate slides using glycerol as the embedding medium. Identification at species level and drawings were done using a DMR Leica microscope equipped with a camera lucida and interference contrast with a maximum magnification of 1600 .

The type material has been deposited in the collection of the Forschungsinstitut Senckenberg (Frankfurt, Germany). The type material of Mesocletodes robustus (collection no. Cop 52) examined was kindly provided by Prof. Dr. F.D. Por from the Hebrew University of Jerusalem in Israel. Abbreviations used in the present paper are: aesthetasc (aes), cephalothorax (cphth), endopod (enp), exopod (exp), baseoendopod (basenp), antennula (A1), antenna (A2), mandibula (md), maxillula ( $\mathrm{mxl}$ ), maxilla (mx), maxilliped (mxp), pereiopods 1-6 (P1-P6), STE (Subapical Tubulate Extension, as described by Huys (1996) for Superornatiremidae).

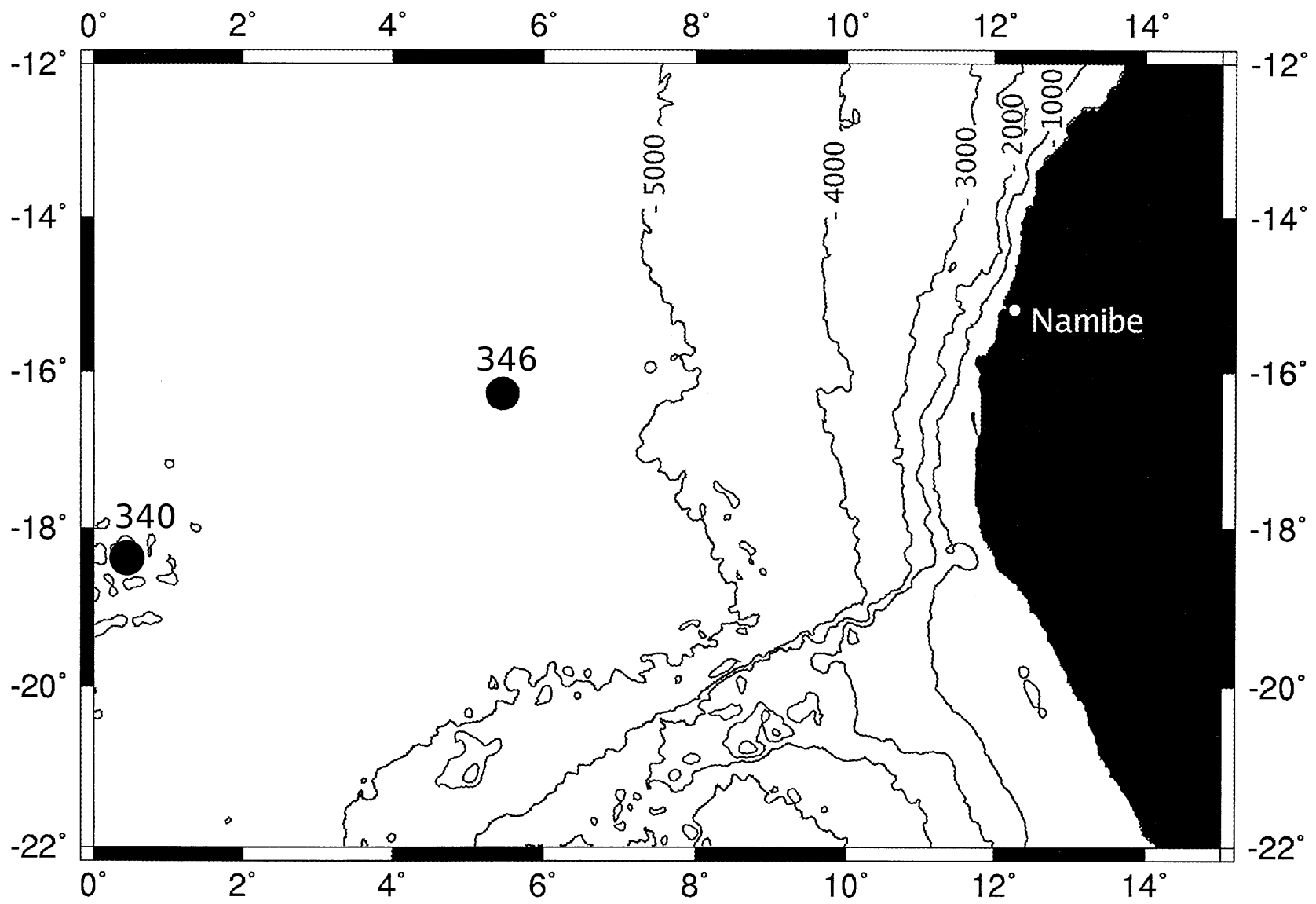

FIGURE 1: Positions of two stations at the DIVA 1 expedition containing the species studied (stations 340 and 346 ). 


\section{Taxonomy}

\section{Argestidae Por, 1986 \\ Mesocletodes Sars, 1909}

Type species: Mesocletodes irrasus (T. Scott, 1894) (described as Cletodes irrasa)

Additional species: In addition to the 4 herein new described species, Mesocletodes contains 32 species to date.

Diagnosis (amended by the authors). Body of subcylindric form, distal edge of body somites with many spinules close to hyaline frill, integument thin and flexible. Cphth comparatively short, rostrum small. Telson large, square. Furcal rami longer than broad. seta VII in the proximal third. Antennula: 7-8-segmented, second segment with strong protrusion bearing 1 strong bipinnate seta pointing backwards. Antenna with basis or allobasis, exp at most 1-segmented with at most 2 setae. Mandibula: palpus with exp and enp at most 1 -segmented, elements of gnathobase form broad grinding face. Maxilla proximal endite with only 1 seta. Mxp stenopodial, with strong claw distally. Swimming legs: Enp at most biarticulate, small, equal in armature at each leg but increasing in length from P2-P4. Exp 3-segmented, of P1 fairly small, of P2-P4 long and slender with slender inner setae. P1 exp3 with 4 setal elements only, spines with Subapical Tubulate Extensions. P5 exp long and slender, inner lobe of basenp barely protruding. 1 egg sack with 2-40 eggs.

\section{Mesocletodes angolaensis sp. nov.}

(Figs 2-6)

Etymology. The species name refers to the sampling location, the Angola Basin.

Locus typicus: Angola Basin (off Angola), RV „Meteor“, Cruise M-48/1, 27.07.2000.

Holotype: 1 male, dissected, mounted on 9 slides, coll. no. SMF $31430 / 1-9$ at station $346 / 1\left(16^{\circ} 17^{\prime}\right.$ S, $\left.05^{\circ} 27^{\prime} \mathrm{E}, 5389 \mathrm{~m}\right)$.

Description of male. Habitus (Figs 2 A, C, D) of cylindrical shape. Body length $642 \mu \mathrm{m}$. No clear distinction between prosome and urosome. Distal margins of cphth and free thoracic somites with denticulated, textured hyaline frill (Fig. 2B) and, except the penultimate somite, with fine, long sensilla. Urosomites with long spinules inserting just anteriorly of the hyaline frill. Rostrum not protruding, with 2 sensilla. Cphth without cuticular process, dorsally and laterally with slight depressions, cuticula with nearly symmetric pattern and symmetrically arranged sensilla. Ventral margin of cphth with small spinules and few sensilla. Telson nearly square from dorsal view, slightly tapering posteriorly, ventrally with spinules, dorsally with strong, cuticular process (Fig. 6A). Cuticular process on telson with basal swelling, distally peaked, long and narrow. Laterally with 1 sensillum on each side. Lateral edges of pleurotergites of P2-P4 bearing prosomites with thickened cuticula and several spinules. P3-P4 bearing somites with 2 dorsal hyaline protrusions each bearing a long sensillum and, laterally of these, a row of spinules. P5 bearing somite laterally with 2 rows of small spinules and few strong spinules close to the hyaline frill.

A1 (Fig. 3A) 7-segmented, haplocer, acrothek on segments IV and VII. First segment without seta, ornamented with strong spinules proximally and subdistally, with small spinules subdistally on anterior face. Second segment with a strong protrusion bearing a strong, bipinnate seta. Segment III very short. Aes of segment IV extremely elongate and large. Segments IV and V with 2 and 1 tripinnate seta(e) respectively. Segments IV-VII arranged in a loop. Spines of A1 with 1 STE each.

Setal Formula: I:0, II:7, III:3, IV:5+Aes, V:2, VI:2, VII:7+Aes.

A2 (Fig. 3B) with basis, seemingly without exp. Enp1 with 6 long spinules. Enp2 with 3 long and several small spinules, 2 medial spines with 1 STE each, terminally with 4 bipinnate setae, 2 of which geniculated.

Mouthparts atrophied, could not be traced due to their strong reduction. 


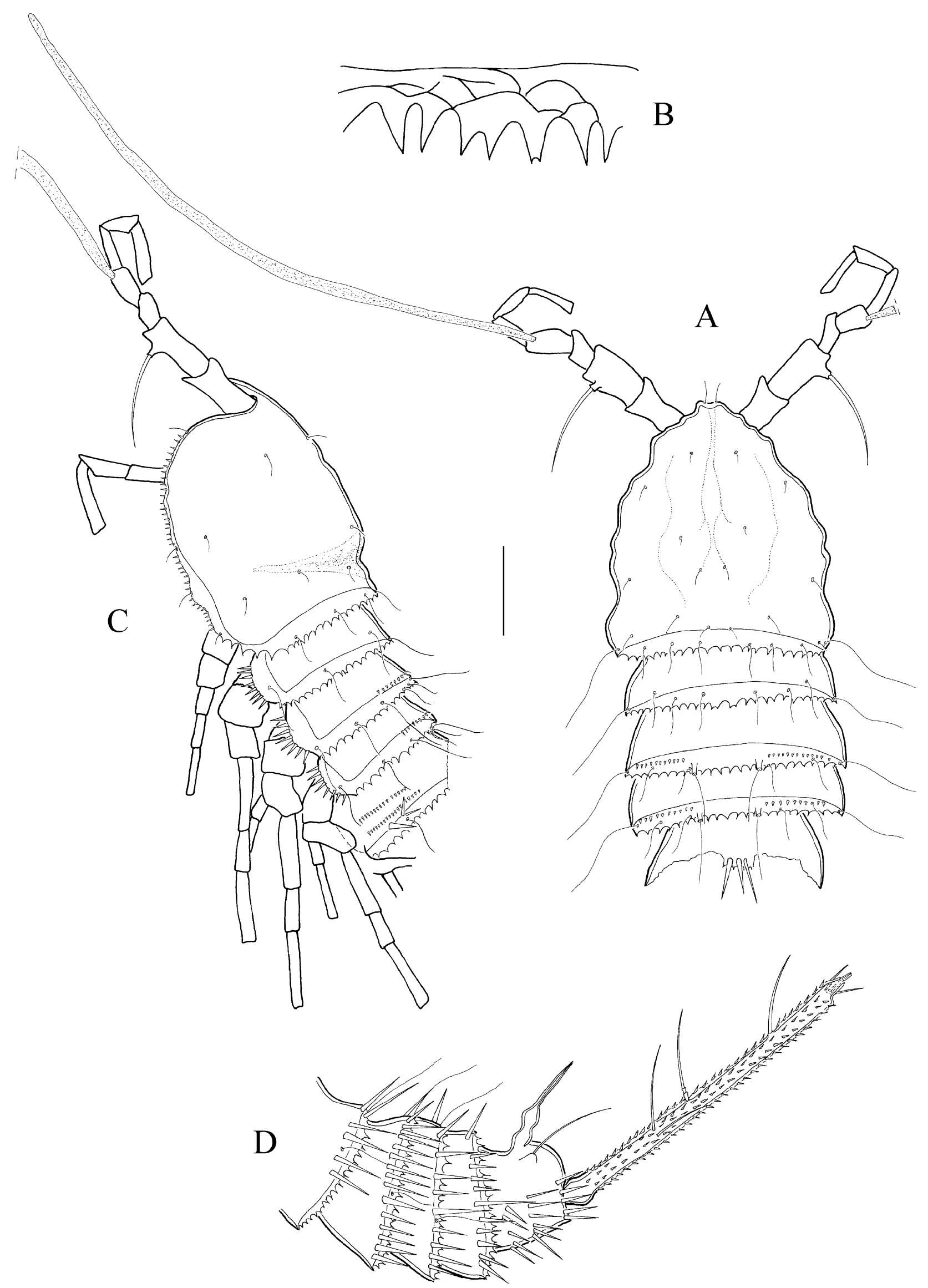

FIGURE 2: Mesocletodes angolaensis sp. nov., male. A, habitus dorsal view, cephalothorax and thorax; B, structure of hyaline frill at distal margins of body somites; C, habitus lateral view, cephalothorax and thorax; D, habitus lateral view, urosome; scale bars: $50 \mu \mathrm{m}$. 


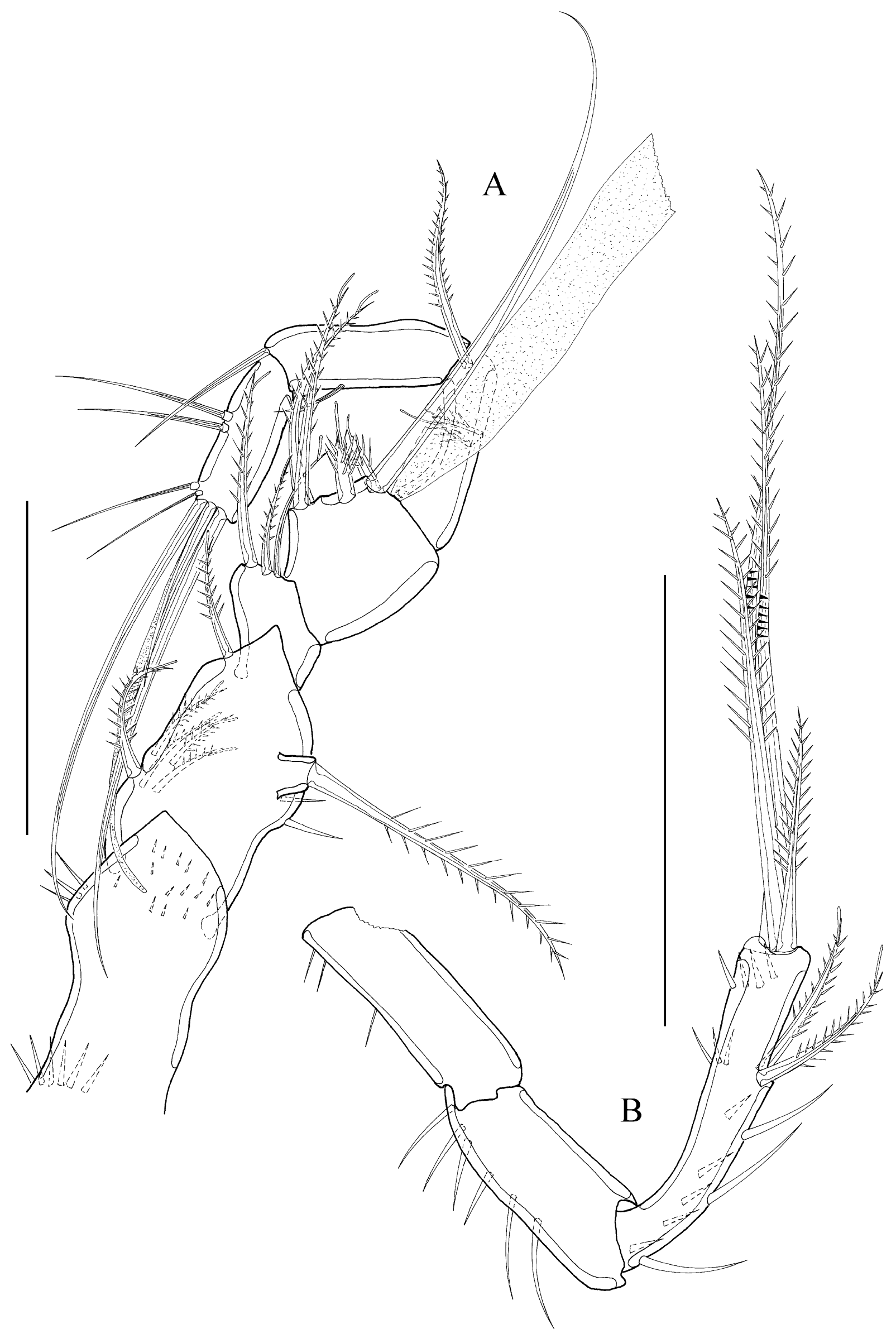

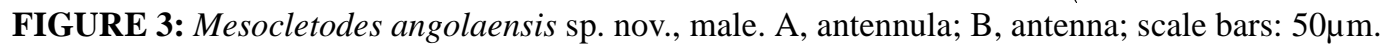




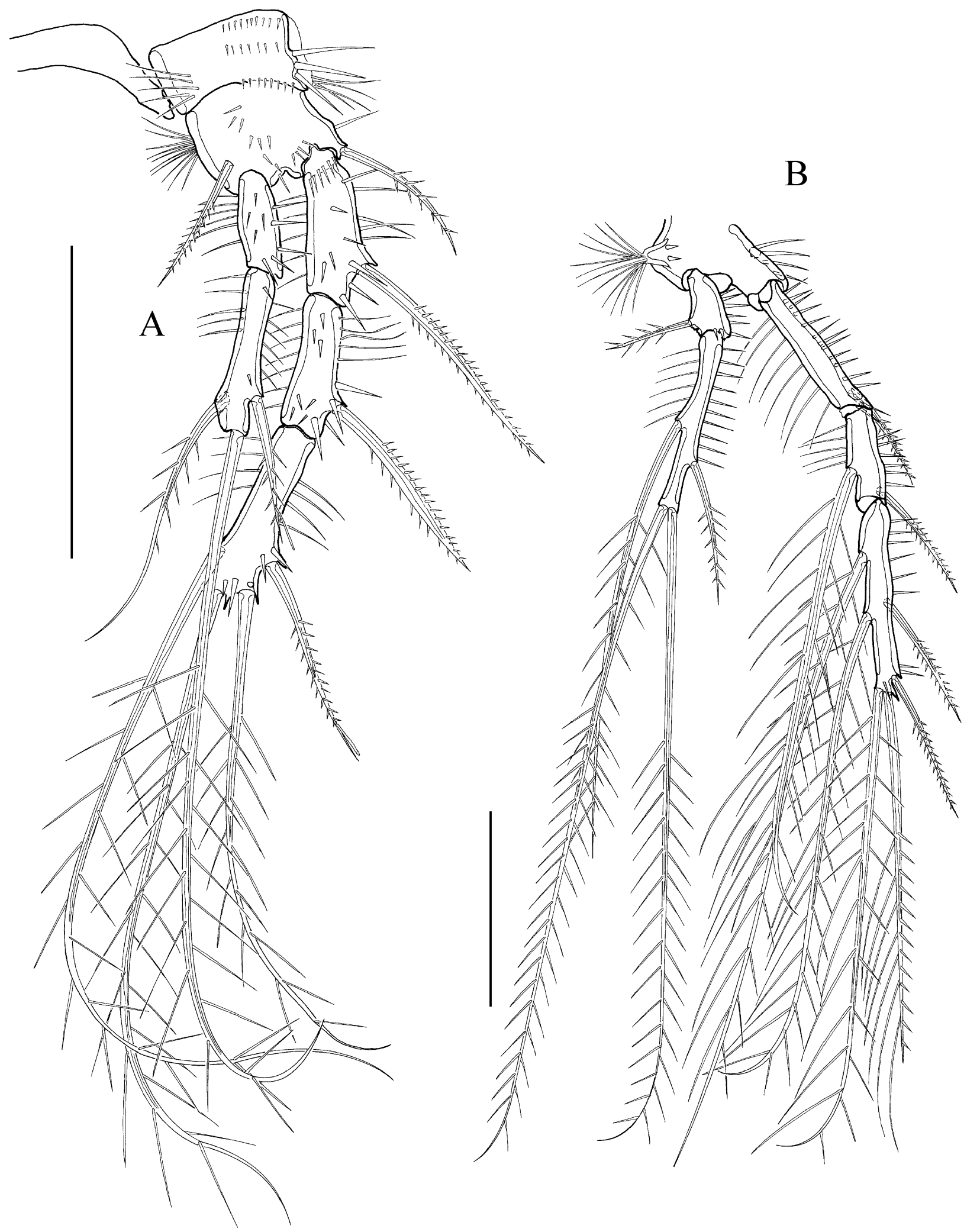

FIGURE 4: Mesocletodes angolaensis sp. nov., male. A, P1; B, P2; scale bars: 50 $\mu \mathrm{m}$. 

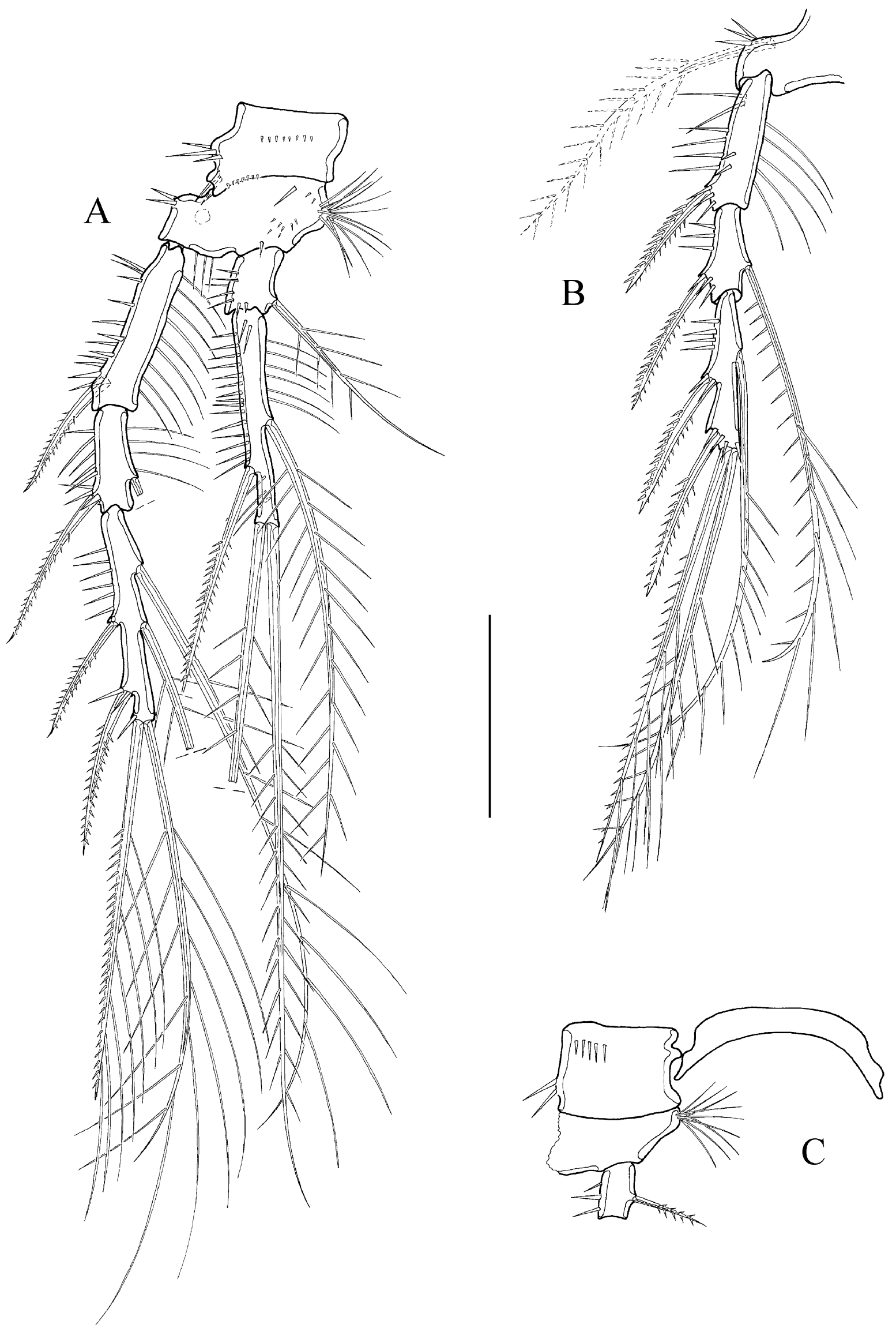

FIGURE 5: Mesocletodes angolaensis sp. nov., male. A, P3; B, P4; C, P4 coxa and basis; scale bar: 50 $\mu \mathrm{m}$. 


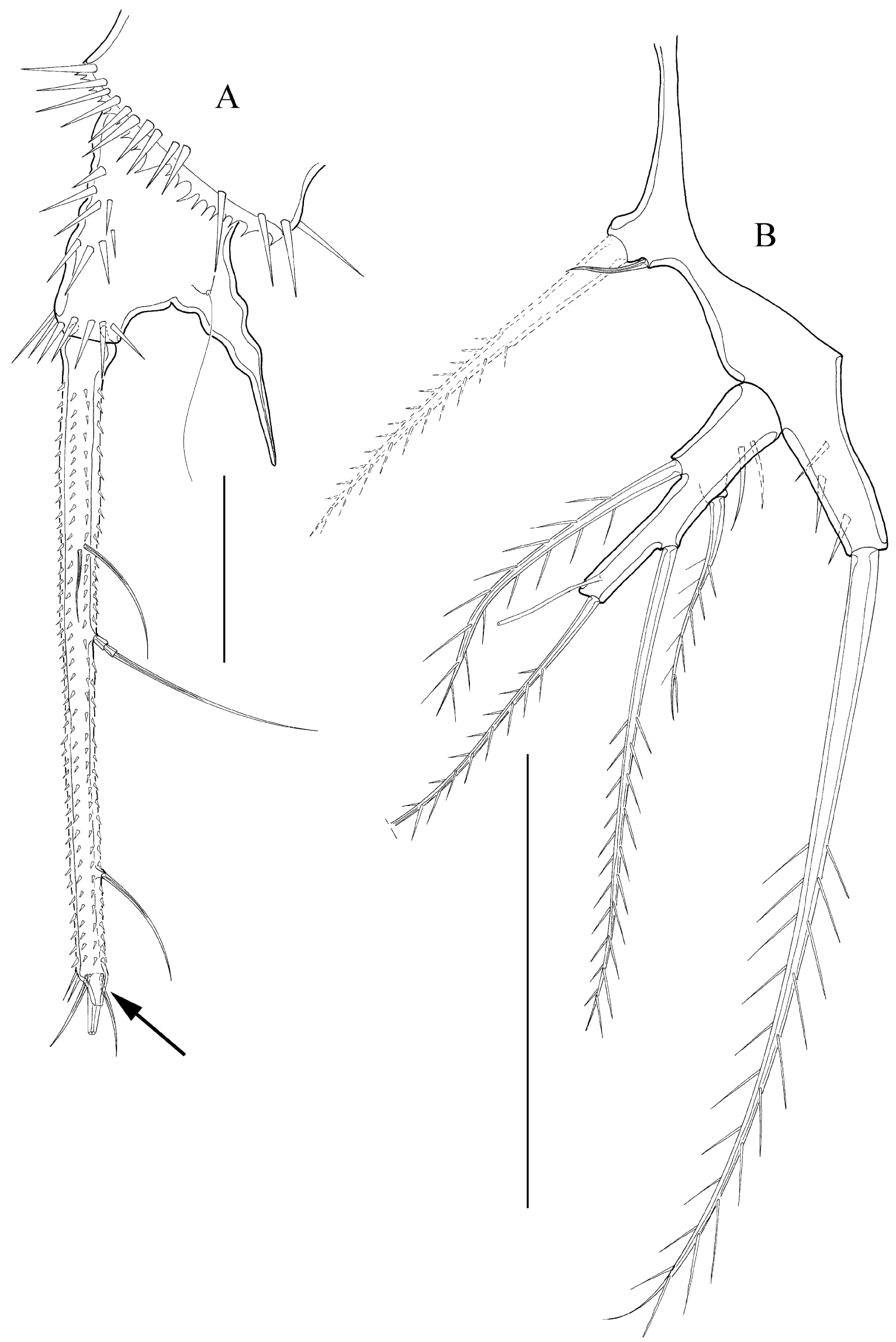

FIGURE 6: Mesocletodes angolaensis sp. nov., male. A, telson and furcal rami lateral view, arrow highlighting distal tube pore; B, P5; scale bars: $50 \mu \mathrm{m}$. 
P1 (Fig. 4A) coxa with several rows of spinules, with fine spinules close to inner and with coarser spinules close to outer margin. Basis at inner margin with setular tuft, with 1 inner and 1 outer spine. Exp 3segmented. Exp1 and Exp2 without inner armature. Exp3 with 1 outer bipinnate spine with STE, 2 terminal and 1 inner, bipinnate seta. Enp 2-segmented. Enp1 without inner seta, Enp2 with 1 inner, 1 terminal and 1 outer, bipinnate seta. Outer seta short and with STE. All segments with inner setules and outer spinules. Spinules near insertion of spines. Intercoxal sclerites are U-shaped and bare. Setal formula as in Table 1.

TABLE 1: Mesocletodes angolaensis sp. nov. setal formula of swimming legs P1-P5

\begin{tabular}{lll}
\hline & Exp & Enp \\
\hline P1 & I-0, I-0, I-2-1 & $0-0,1-1-1$ \\
P2 & I-0, I-1, II-2-2 & $0-1,1-2-1$ \\
P3 & I-0, I-1, II-2-2 & $0-1,1-2-1$ \\
P4 & I-0, I-1, II-2-1 & $0-1, ?$ \\
P5 & $2-1-1$ & $1-1-0$ \\
\hline
\end{tabular}

P2-P4 (Figs 4B; 5A, B, C) coxa with spinules as shown for P3. Basis with inner setular tufts and outer seta (as illustrated for P4). Exp 3-segmented. Exp1 with fine spinules at inner margin. Exp2 with inner, bipinnate seta. Exp3 with 2 outer, bipinnate spines, 1 terminal, unequally bipinnate spine and 1 bipinnate seta, with 2 (P2 and P3) or 1 (P4) inner, bipinnate seta(e). Enp biarticulate. Enp1 with inner, bipinnate seta and fine, outer spinules. Enp2 of P2 and P3 with 4 bipinnate setae, Enp2 of P4 lost during dissection. Spinules near insertion of spines. Intercoxal sclerite as in P1. Setal formula as in Table 1.

P5 (Fig. 6B) outer part of basenp with setophore, 3 spinules and long bipinnate seta. Inner part of basenp barely protruding, with 1 long, strong, inner seta and 1 short, bare, outer seta. Exp about 4 times longer than basal width , proximally with 2 long spinules, 2 outer, 1 terminal and 1 inner setae and 1 STE. Setal formula as in Table 1.

P6 reduced to 1 seta.

Furcal rami (Fig. 6A) about 13 times longer than wide at their insertion. Entirely covered by spinules, insertion surrounded by coarse spinules of anal somite. Furcal ramus with 7 setae: I and II close together laterally in proximal third, seta III inserted subdistally dorsolaterally, IV, V and VI inserting terminally, VII dorsally in the middle. Setae I, II, III, IV and VI bare, Seta V broken, seta VII triarticulated and bare. Furcal ramus with tube pore terminolaterally (highlighted by arrow in Fig. 6A).

Female unknown.

\section{Mesocletodes bicornis sp. nov.}

(Figs 7-11)

Etymology. The name refers to the double cuticular process on the cephalothorax.

Locus typicus: Angola Basin, (off Angola), RV „Meteor“, Cruise M-48/1, 27.07.2000.

Holotype: 1 female, mounted on 1 slide, coll. no. SMF 31426/1 at station 346/4 (16 $16.9^{\prime}$ 'S / $05^{\circ} 27.0^{\prime} \mathrm{E}$, $5389 \mathrm{~m})$.

Paratypes: 1 female, dissected, mounted on 12 slides, coll. no. SMF 31427/1-12 at station 346/2 (16 $\left.{ }^{\circ} 17.0^{\prime} \mathrm{S} / 05^{\circ} 27.0^{\prime} \mathrm{E}, 5389 \mathrm{~m}\right)$; 1 female, dissected, mounted on 6 slides, coll. no. SMF 31431/1-6 at station 346/8(16 ${ }^{\circ} 17.0^{\prime} \mathrm{S} / 05^{\circ} 27.0^{\prime} \mathrm{E}, 5390 \mathrm{~m}$ ); 1 female, mounted on 1 slide, coll. no. SMF 31432/1 at station 346/2 (16 $\left.17.0^{\prime} \mathrm{S} / 05^{\circ} 27.0^{\prime} \mathrm{E}, 5389 \mathrm{~m}\right) ; 1$ female, mounted on 1 slide, coll. no. SMF 31433/1 at station 346/5 $\left(16^{\circ} 17.0^{\prime} \mathrm{S} / 05^{\circ} 27.0^{\prime} \mathrm{E}, 5389 \mathrm{~m}\right)$; 1 female, mounted on 1 slide, coll. no. SMF 31434/1 at station 346/1 (16 $\left.17.0^{\prime} \mathrm{S} / 05^{\circ} 27.0^{\prime} \mathrm{E}, 5389 \mathrm{~m}\right)$. 


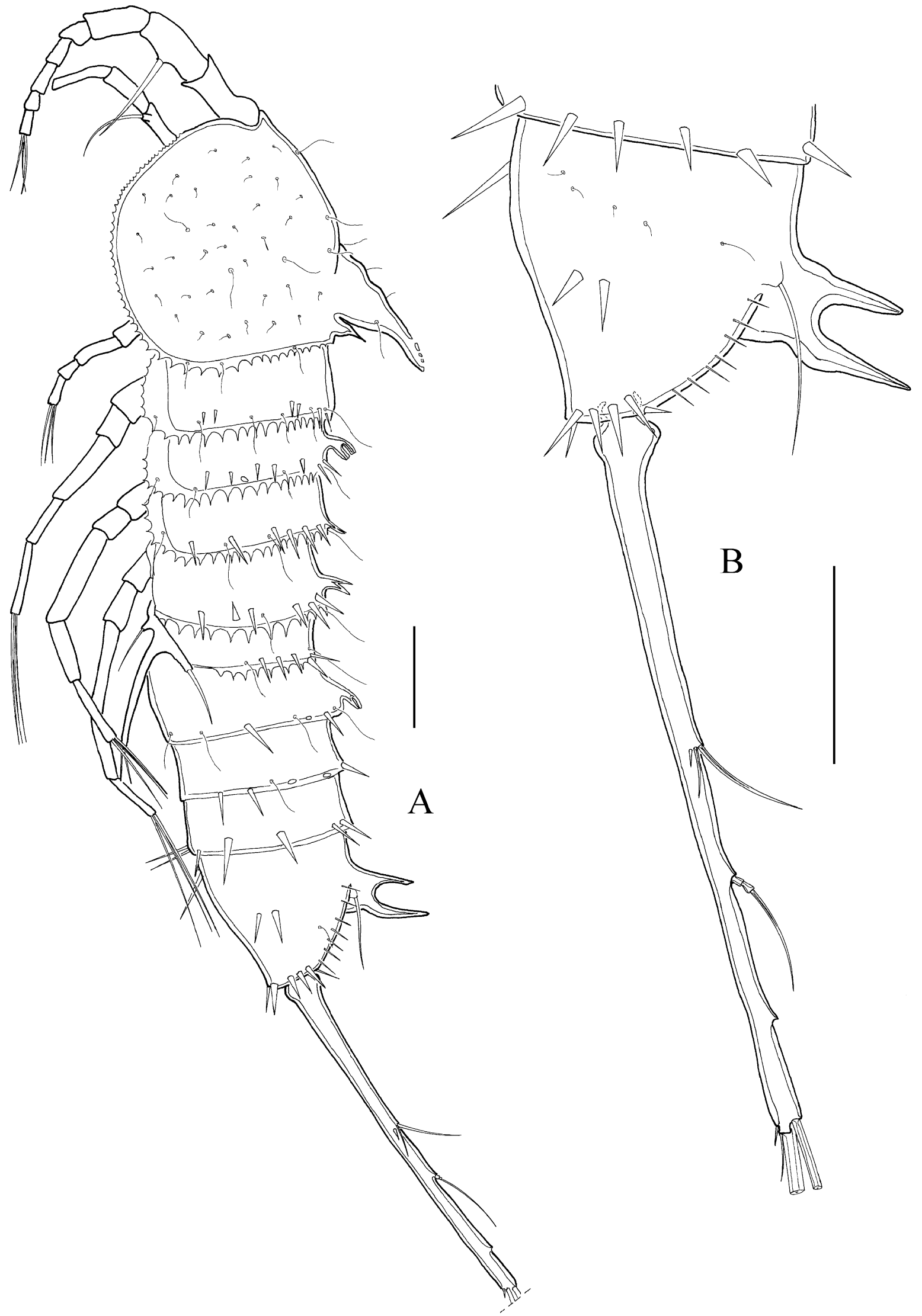

FIGURE 7: Mesocletodes bicornis sp. nov., female (holotype). A, habitus lateral view; B, telson and furcal rami, lateral view; scale bar: $50 \mu \mathrm{m}$. 


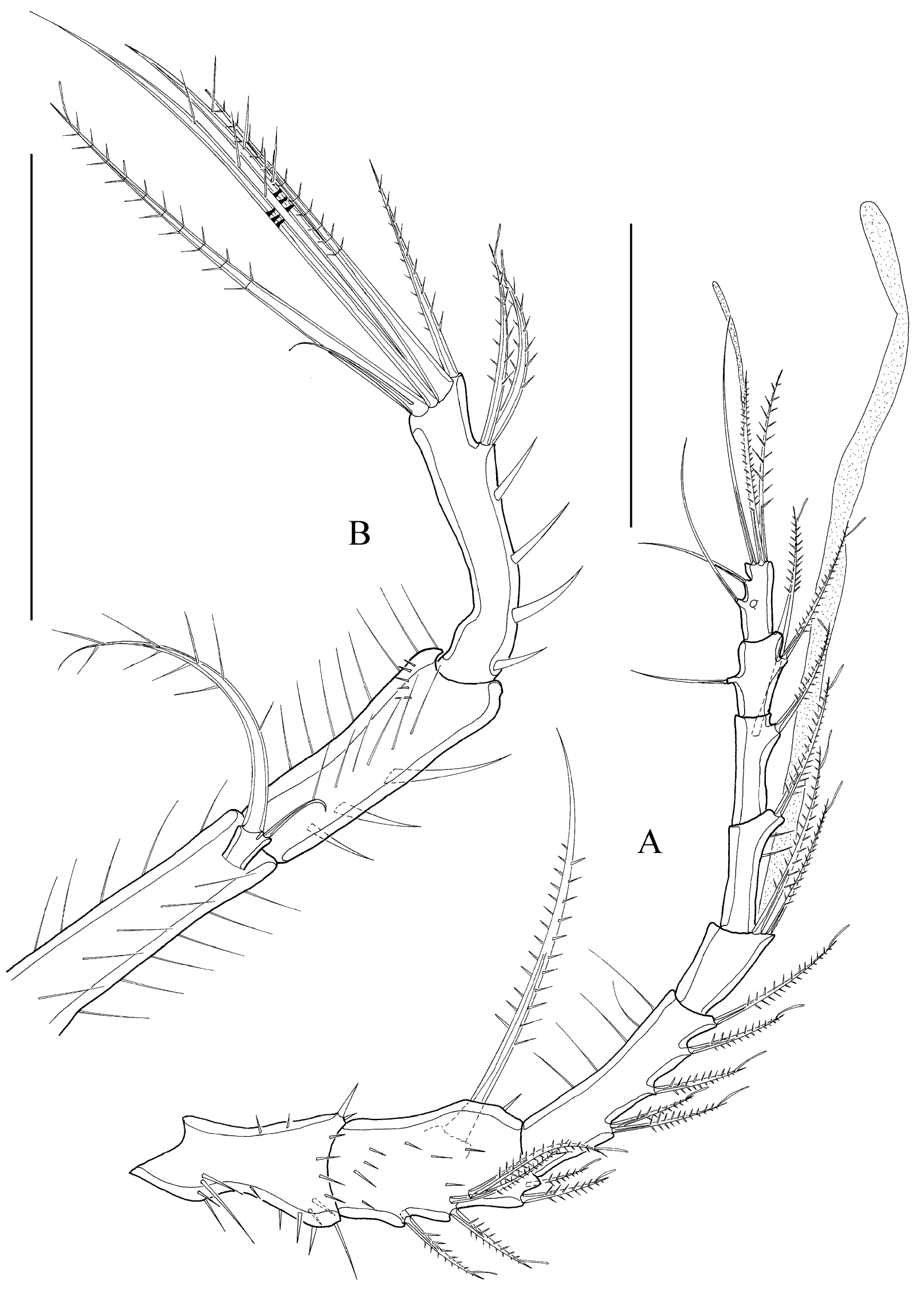

FIGURE 8: Mesocletodes bicornis sp. nov., female (paratype). A, antennula; B, antenna; scale bars: 50 $\mathrm{mm}$. 


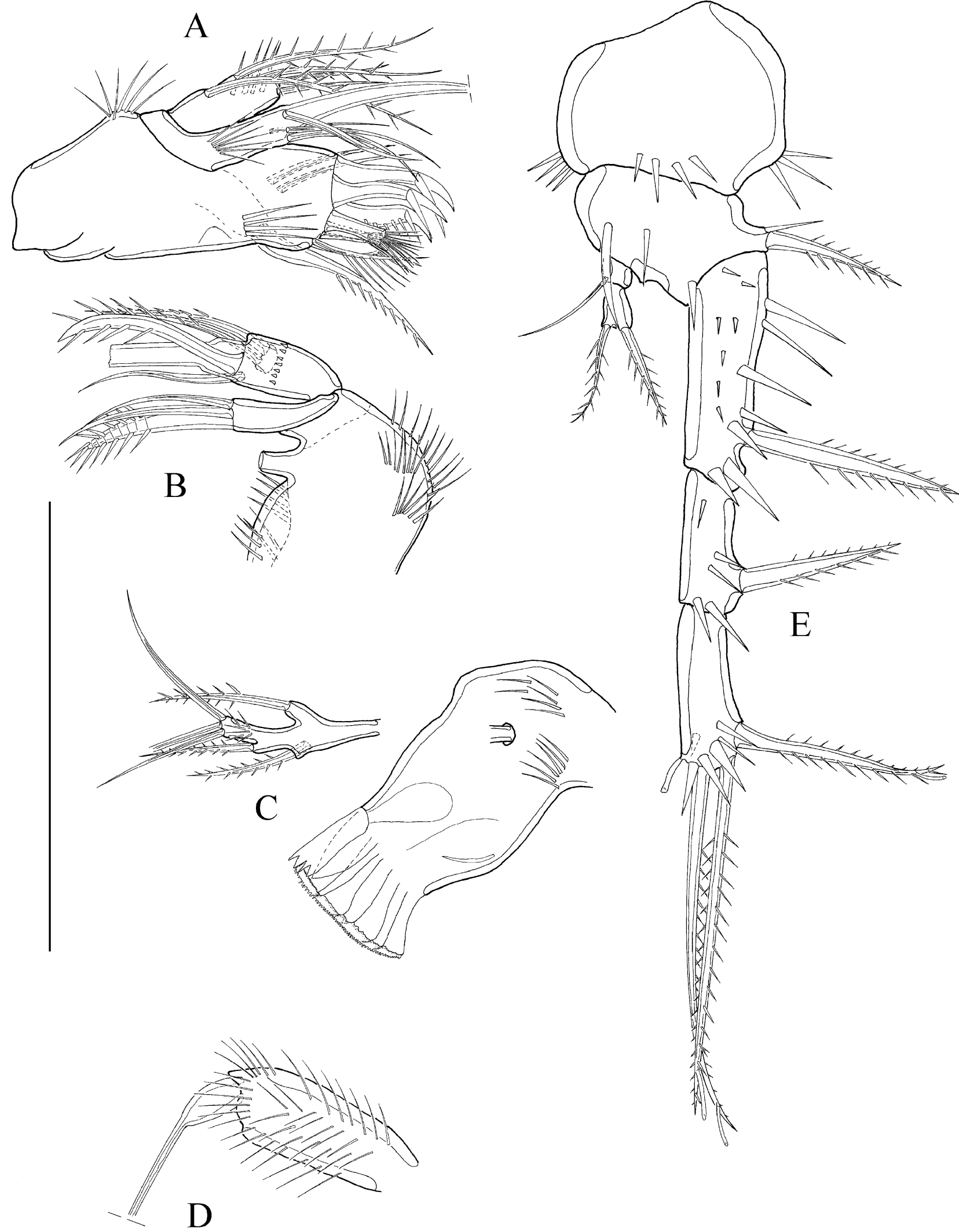

FIGURE 9: Mesocletodes bicornis sp. nov., female (paratype). A, maxillula; B, maxilla; C, mandibula; D, maxilliped; E, P1; scale bars: $50 \mu \mathrm{m}$.

Description of female. Habitus (Fig. 7A) of cylindrical shape, no clear distinction between prosome and urosome. Body length $660 \mu \mathrm{m}$. Rostrum small, not protruding, with 2 sensilla. Cphth dorsally with bifid, 
cuticular process, anterior part triangular, curved and pointing posteriorly, posterior part small and stout, triangular. Distal margins of cphth to second urosomite with denticulated, hyaline frill, the remaining urosomites with bare hyaline frill. Long sensilla on distal margins of body somites, except the penultimate one. P3-P5 bearing somites and second urosomite dorsally with bifid cuticular processes. Rows of spinules along posterior margins of somites, spinules increasing in length posteriorly. Telson square, dorsally with bifid, cuticular process peaked upward with posterior tip longer than the anterior one.

A1 (Fig. 8A) 8-segmented, acrothek on segments 4 and 8. First segment without seta, proximally with corona of spinules and several spinules spread over the segment. Second segment with a strong protrusion bearing a strong, bipinnate seta. Third segment elongate, with 5 fine, long spinules at inner margin of the segment. Spines of A1 with 1 STE each.

Setal formula: I:0, II:7, III:5, IV:2+Aes, V:1, VI:2, VII:3, VIII:6+Aes.

A2 (Fig. 8B) basis with fine spinules. Exp incompletely fused to basis, 1-segmented, with 1 long, bipinnate and 1 short, bare seta. Enp1 with many fine, long spinules, a corona of spinules in the distal part and 3 strong spinules at the outer margin. Enp2 with 4 strong outer spinules, 2 medial bipinnate spines with 1 STE each and 6 terminal elements: 1 outer, bipinnate spine, 1 annulate seta, 2 geniculated setae with 3 pinnae each, 1 annulate seta distally with STE, seta fused to a small, bare seta at the base.

Md (Fig. 9C) gnathobase with broad grinding face. Dorsally with transformed denticulated seta, beneath 2 spoonlike setae, followed by several strong toothlike elements. Palpus 1-segmented, with 1 bipinnate basal seta, 1 bipinnate exopodal seta and 4 endopodal setae, 3 of these located terminally.

Mxl (Fig. 9A) arthrite of the praecoxa with long spinules and 10 armature elements: 2 bare surface setae (depicted beneath), 2 strong, tooth like setae with 1 strong spinule each, 1 strong, tooth like seta with 1 spinule and several strong pinnae, 2 brushlike setae, 1 unipinnate seta, 1 bare, 1 unipinnate, single seta. Coxa with spinules at the base of arthrite, with long spinules and 5 setae, strongest seta fused to coxa. Basis with 5 bipinnate setae and 4 spinules.

Mx (Fig. 9B) syncoxa with 2 endites. Proximal endite with 1 seta (seta lost during dissection), distal endite with 3 setae: Endite drawn out into strong claw with two accompanying bare setae. Basis with a row of small spinules and 3 setae: main seta incompletely fused to basis, 1 strongly bipinnate seta and 1 bare slender seta subterminally. Enp 1-segmented, very small, with 2 bipinnate setae.

Mxp (Fig. 9D) syncoxa lost during preparation. Basis with many fine spinules, unarmed. Enp 1segmented, fused to strong claw.

P1 (Fig. 9E) coxa with several spinules. Basis with 1 inner and 1 outer spine. Exp 3-segmented. Exp1 and exp2 without inner armature. Exp3 inner seta transformed to tube pore. Exp3 with 3 bipinnate spines with 1 STE each. Enp biarticulate. Enp1 with inner seta. Enp2 with 2 terminal setae. Setal formula as in Table 2.

P2-P4 (Figs 10A-C) coxae with several spinules (P2 lost during preparation. However, it was observed that P2 and P3 were identical with respect to the setation). Bases with outer seta and inner setular tufts. Exp 3segmented. Exp1 P3 and P4 with few fine, inner spinules. Exp2 with inner, bipinnate seta and outer spine. Exp3 with 2 bipinnate, outer spines, 2 bipinnate setae terminally and 2 (P2 and P3) or 1 (P4) inner bipinnate setae. Enp biarticulate. Enp1 without seta. Enp2 with 4 bare setae. Spines with spinules at their insertionpoints. Setal formula as in Table 2.

TABLE 2: Mesocletodes bicornis sp. nov. setal formula of swimming legs P1-P5.

\begin{tabular}{lll}
\hline & Exp & Enp \\
\hline P1 & I-0, I-0, I-2-1 & $0-1,0-2-0$ \\
P2 & I-0, I-1, II-2-2 & $0-0,1-2-1$ \\
P3 & I-0, I-1, II-2-2 & $0-0,1-2-1$ \\
P4 & I-0, I-1, II-2-1 & $0-0,1-2-1$ \\
P5 & $3-1-1$ & $1-1-1$ \\
\hline
\end{tabular}




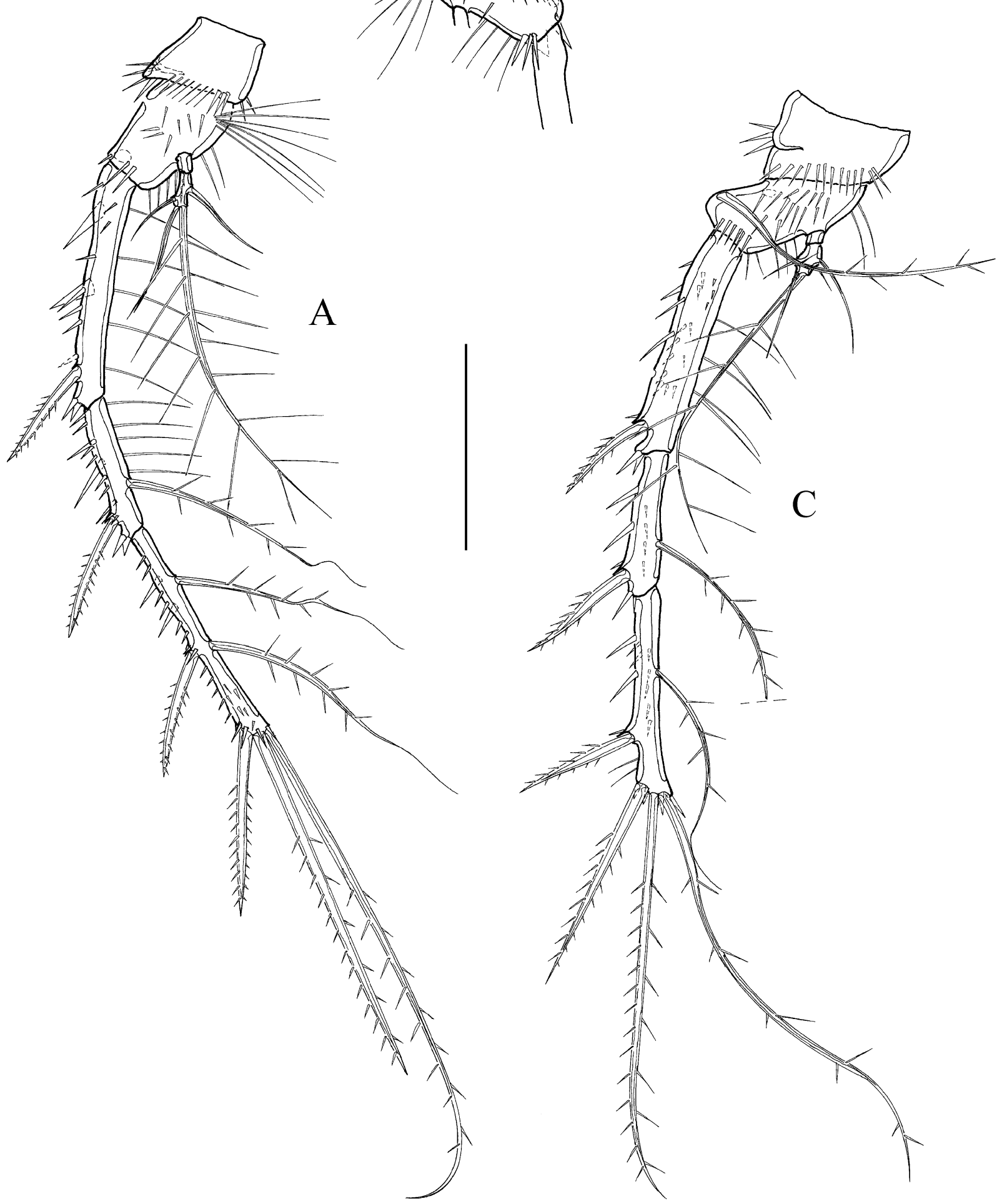

FIGURE 10: Mesocletodes bicornis sp. nov., female (paratype). A, P3; B, P3 coxa and basis; C, P4; scale bar: 50 $\mu$ m.

P5 (Fig. 11) basenp with several spinules. Outer lobe of basenp with setophore bearing 3 spinules and 1 outer seta. Inner lobe not protruding, with 1 long inner, 1 long median, bipinnate and 1 short, outer seta. The outer and median seta are close to each other, the long, inner seta separated from the former two elements. 
Exp approximately 5 times longer than broad, with 5 setae and 1 apical tube pore. Exp sparsely covered with spinules. Setal formula as in Table 2.

Furcal rami (Fig. 7B) approximately 13 times longer than broad (the widest part measured at its base), the insertion surrounded by spinules of anal somite. Furcal ramus with distal tube pore and 7 setae: setae I and II in the middle of caudal ramus with spinules at their insertions, seta III subdistally, setae IV and V distally, seta VI distally and arising ventrally, seta VII dorsally in distal half. Setae I and II bare, setae III, IV, V lost during sample treatment, seta VI bare, VII triarticulate and bare.

Male unknown.

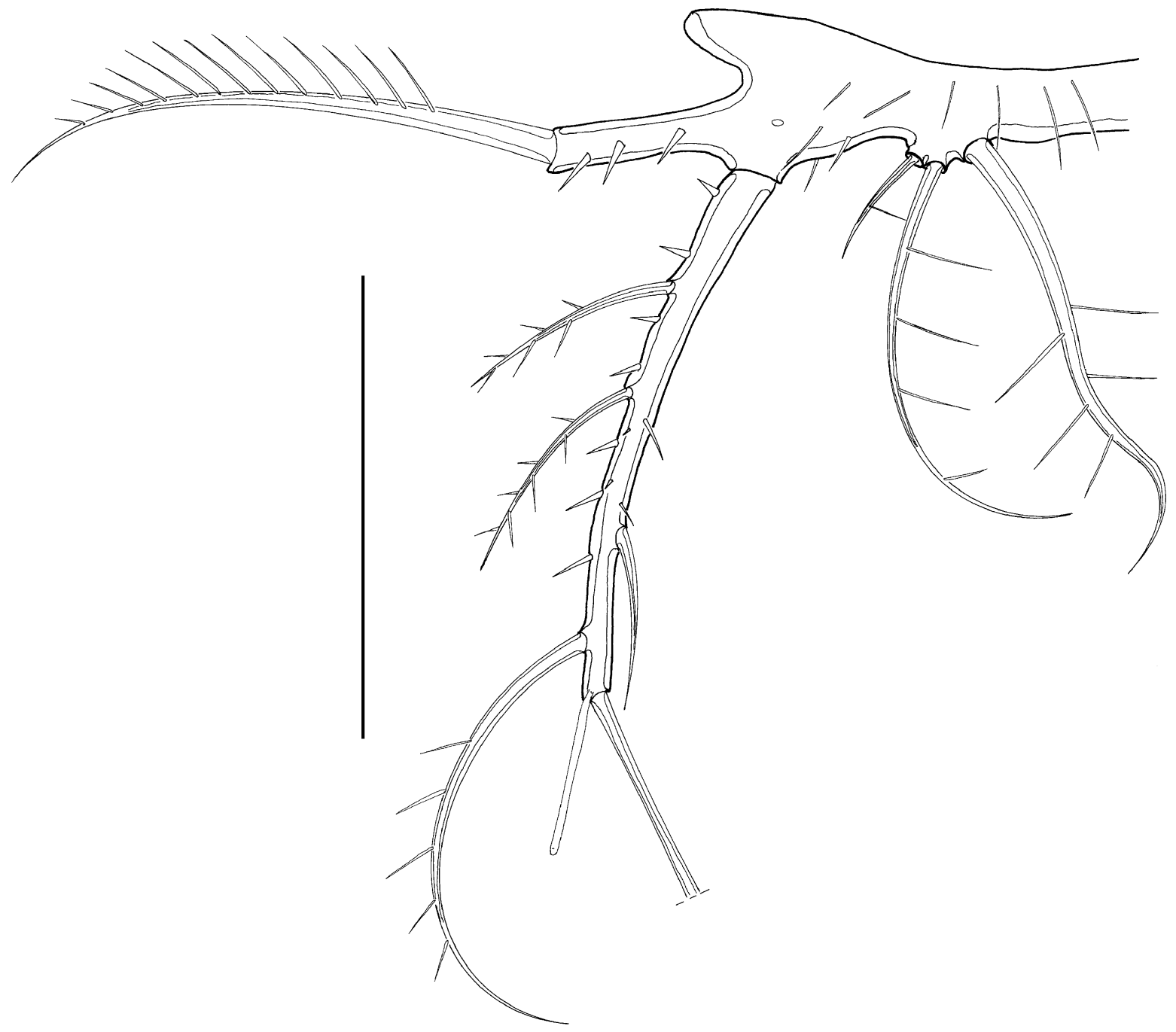

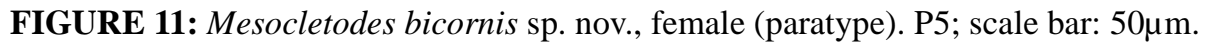

\section{Mesocletodes dorsiprocessus sp. nov.}

(Figs 12-17)

Etymology. The name refers to the bifid cuticular processes in P2-P5-bearing somites and first urosomite.

Locus typicus: Angola Basin, (off Angola), RV „Meteor“, Cruise M-48/1, 27.07.2000.

Holotype: 1 female, dissected, mounted on 12 slides, coll. no. SMF 31428/1-12 at station 346/4 (16 $\left.16.9^{\prime} \mathrm{S} / 05^{\circ} 27.0^{\prime} \mathrm{E}, 5389 \mathrm{~m}\right)$.

Paratype: 1 female mounted on 1 slide, coll. no. SMF 31429/1 at station EBS 340 (start: $18^{\circ} 18.3^{\prime} \mathrm{S}$ 004 $41.3^{\prime} \mathrm{E}$; end $18^{\circ} 19.4^{\prime} \mathrm{S} 004^{\circ} 41.9^{\prime} \mathrm{E}, 5395 \mathrm{~m}$ ). 
Description of female. Habitus (Fig. 12A) of cylindrical shape, no clear distinction between prosome and urosome. Body length $1105 \mu \mathrm{m}$. Rostrum small, not protruding, with 2 sensilla. Cphth dorsally with cuticular process, process triangular, curved posteriorly. Distal margins of cphth and body somites with denticulated hyaline frill. Long sensilla on distal margins of body somites, except the penultimate one. Body somites with rows of spinules, increasing in length and breadth posteriorly. P3-P5 bearing somites and second urosomite dorsally with bifid cuticular processes. Telson quadrate, with several strong spinules and bifid cuticular process dorsally, peaked upward, posterior tip longer than anterior. Laterally, 1 sensillum on each side. Genital doublesomite incompletely fused. P2-P4 bearing somites with thickened cuticula near insertion of the legs.

A1 (Fig. 13A) 8-segmented, acrothek on segments 4 and 8 proximally with corona of spinules and several spinules scattered across the surface. Second segment with strong protrusion bearing a strong, bipinnate seta. Third segment elongated. Spines of A1 with 1 STE each. All segments covered by fine spinules.

Setal formula: I:0, II:8, III:5, IV:2+Aes, V:1, VI:3, VII:6; VIII: 6+Aes.

A2 (Fig. 15A) coxa short and unarmed. Basis with fine spinules. Exp 1-segmented, with 2 bipinnate setae. Enp1 and 2 with fine, inner spinules and 4 outer spinules each. Enp2 with 2 medial, bipinnate spines with 1 STE each and 6 terminal elements. 1 outer bipinnate spine, 2 geniculated, bare setae, 1 bipinnate spine, 1 bipinnate spine with STE, spine fused with 1 fine bare seta at the basis.

Paragnaths (Fig. 13B) with few short, fine spinules medially and many very long spinules laterally, ventrally of these long spinules are broad spinules with distal brushes; ventral surface covered in small spinules.

Md (Figs 14B, C) gnathobase with broad grinding face. Dorsally with transformed denticulated seta, beneath 2 spoonlike setae, followed by several strong toothlike elements. Palpus 1-segmented, with spinules and 1 basal seta, 1 exopodal and 1 endopodal seta.

$\mathrm{Mxl}$ lost during preparation.

Mx (Fig. 14A) syncoxa with 2 endites. Proximal endite with 1 seta, distal endite well developed with 3 terminal setae: 1 strongly bipinnate seta incompletely fused to the endite, 1 bipinnate and 1 bare seta. Basis with long spinules and 3 setae: 1 seta incompletely fused to basis, 1 strong seta and 1 bare seta subterminally. Enp 1-segmented, very small, with 2 setae.

Mxp (Fig. 13C) syncoxa with 1 tripinnate seta, many very fine spinules and 3 rows of strong spinules. Basis with long inner spinules and many spinules dorsally. Enp 1-segmented, fused to strong claw (broken off).

P1 (Fig. 16A) coxa with several spinules. Basis with 1inner and 1 outer spine. Exp 3-segmented. Exp1 and 2 inner margin without armature. Exp3 with 2 bipinnate spines with 1 STE each, 1 bipinnate seta terminally and 1 bare inner seta. Enp biarticulate. Enp1 with 1 bare inner seta. Enp2 with 1 bare inner seta and 1 bipinnate and 1 bare seta terminally. Strong spinules at insertions of spines, all segments with fine spinules. Setal formula as in Table 3.

P2-P4 (Figs 16B; 17A, B) coxae with several spinules. Bases with outer seta only. Exp 3-segmented. Exp1 with hairy outer spinules, without inner seta. Exp2 with inner bipinnate seta and outer spine. Exp3 with 2 bipinnate outer spines, 2 bipinnate setae terminally and 2 (P2 and P3) or 1 (P4) inner bipinnate setae. The terminal outer spine of P4 Exp3 is probably broken off. Enp biarticulate. Enp1 with bare inner seta. Enp2 with 3 setae (P2) or with 2 setae (P3 and P4). All spines with spinules at their insertion points. Setal formula as in Table 3.

TABLE 3: Mesocletodes dorsiprocessus sp. nov. setal formula of P1-P5.

\begin{tabular}{lll}
\hline & Exp & \\
\hline P1 & I-0, I-0, I-2-1 & $0-1,1-2-0$ \\
P2 & I-0, I-1, II-2-2 & $0-1,1-2-0$ \\
P3 & I-0, I-1, II-2-2 & $0-1,0-2-0$ \\
P4 & I-0, I-1, II-2-1 & $0-1,0-2-0$ \\
P5 & $3-1-1$ & $1-1-0$ \\
\hline
\end{tabular}




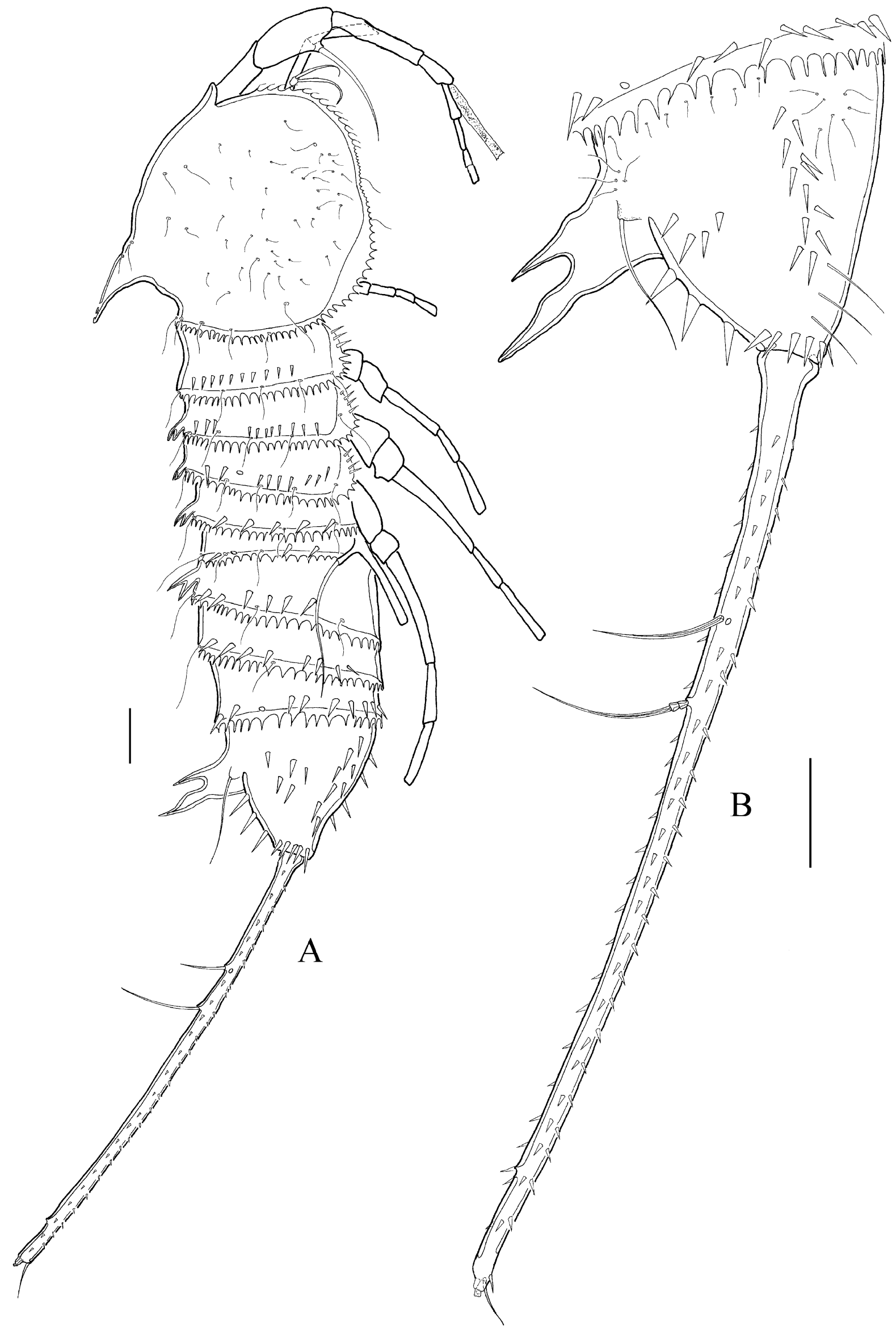

FIGURE 12: Mesocletodes dorsiprocessus sp. nov., female (holotype). A, habitus lateral view; B, telson and furcal rami lateral view; scale bars: $50 \mu \mathrm{m}$. 


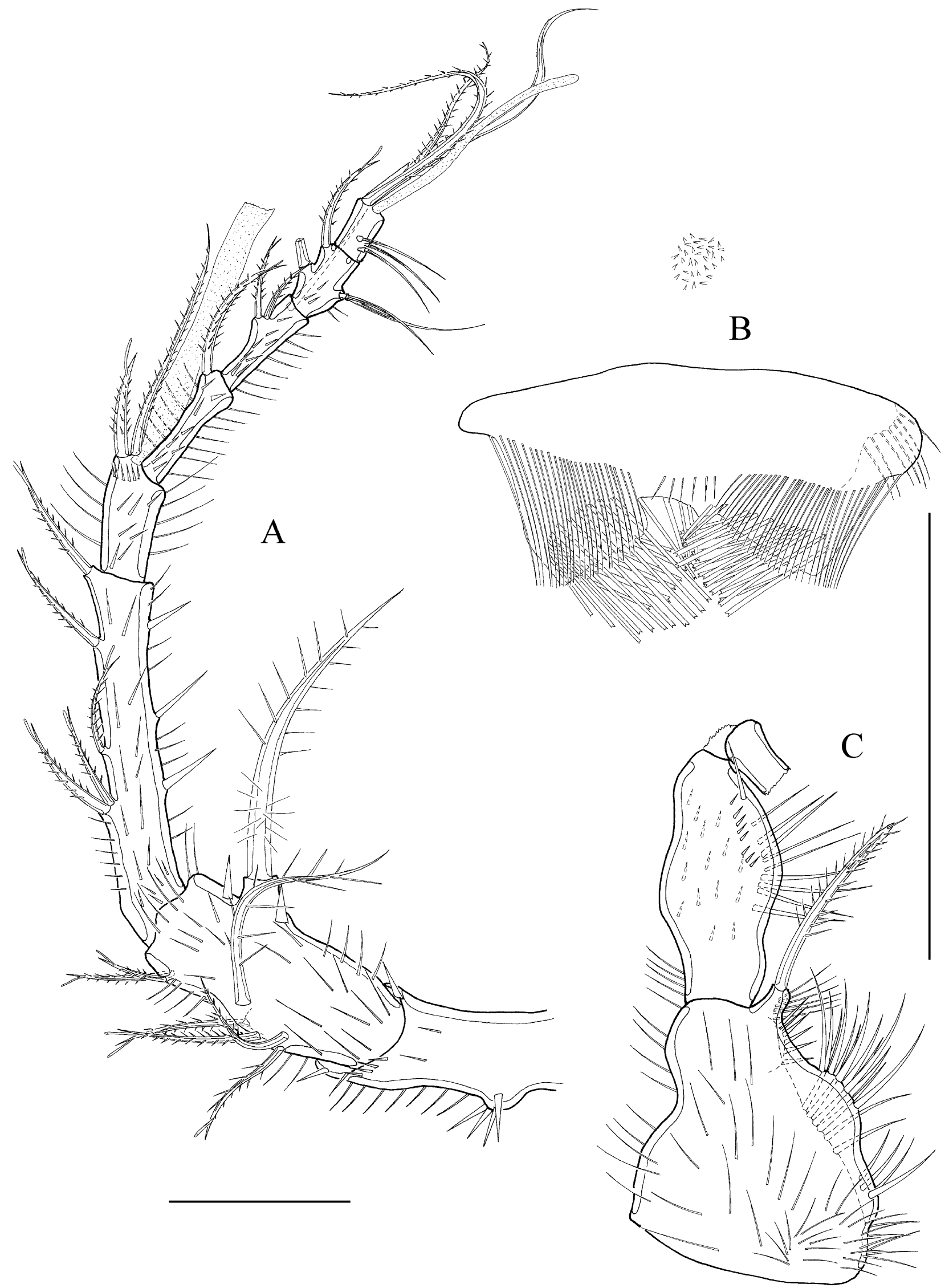

FIGURE 13: Mesocletodes dorsiprocessus sp. nov., female (holotype). A, antennula; B, paragnaths; C, maxilliped; scale bars: $50 \mu \mathrm{m}$. 

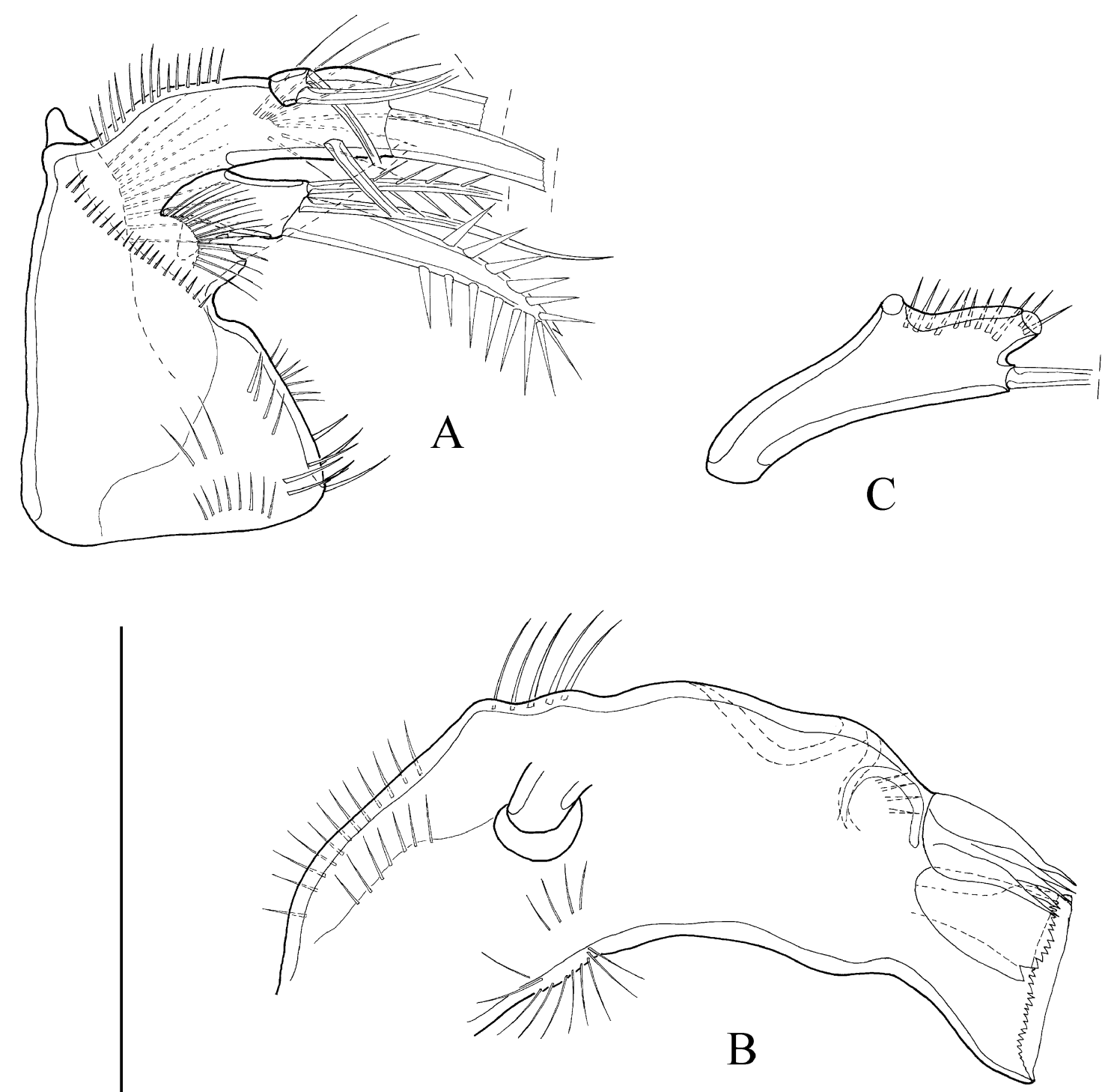

FIGURE 14: Mesocletodes dorsiprocessus sp. nov., female (holotype). A, maxilla; B, mandibula; C, mandibular palpus; scale bar: $50 \mu \mathrm{m}$.

P5 (Fig. 15B) basenp with several spinules. Outer lobe of basenp with setophore bearing 3 spinules and 1 outer seta. Inner lobe not protruding, with 1 short outer and 1 long median bipinnate seta (lost during preparation, only insertion point remained). Net-like structure between inner and outer lobe of basenp. Exp approximately 9 times longer than broad, with 5 setae and 1 terminal tube pore. Exp covered with spinules. Setal formula as in Table 3.

Furcal rami (Fig. 12B) approximately 13 times longer than broad (the widest part measured at its base), the insertion surrounded by spinules of anal somite. Furcal ramus completely covered by spinules, with strong terminal tube pore and 7 setae: I and II in the middle of caudal ramus, seta III subdistally, setae IV, V and VI distally, seta VII dorsally in distal half. Seta I, III, IV and V lost during preparation, seta I and VI bare, seta VII triarticulate and bare.

Male unknown. 


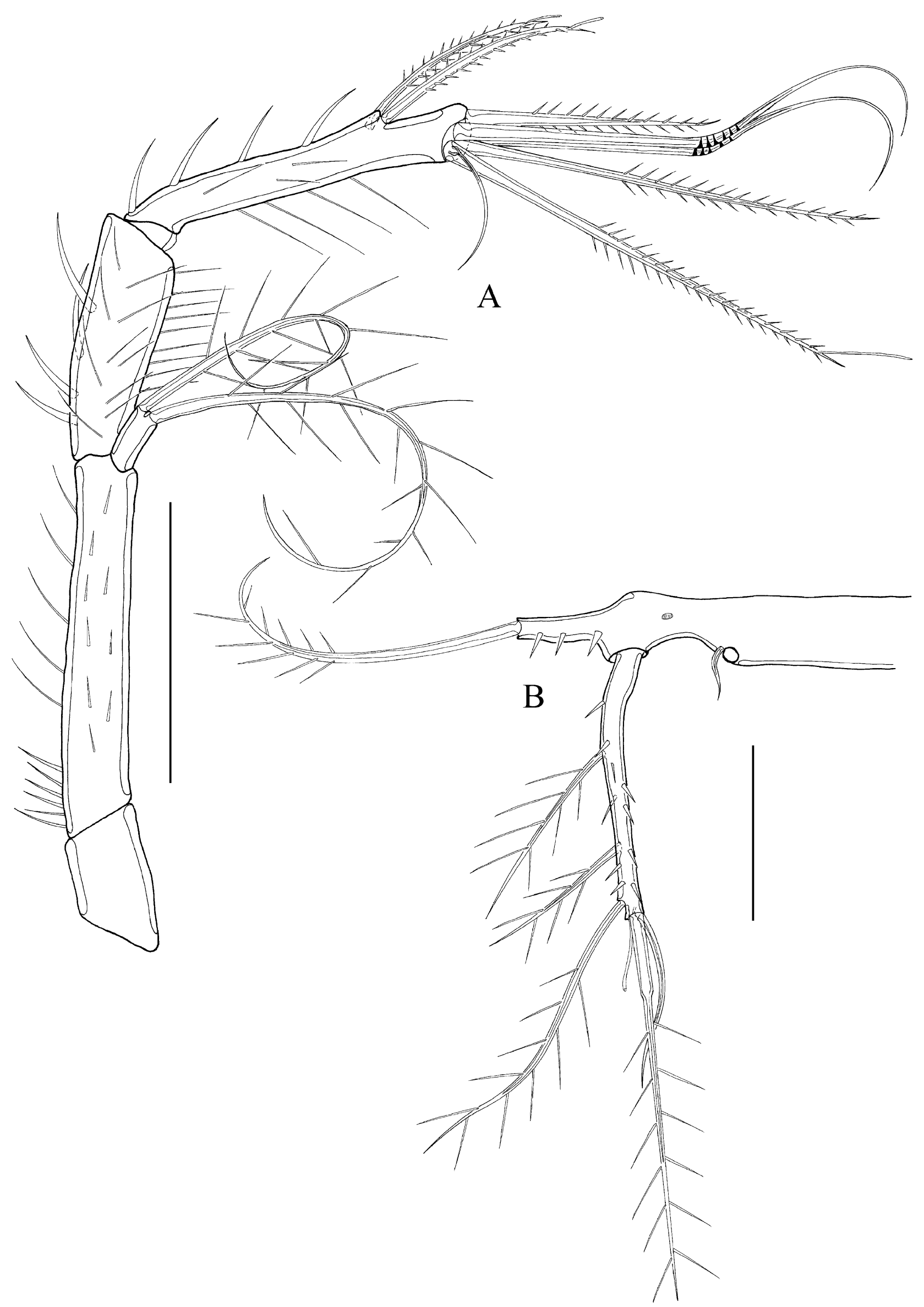

FIGURE 15: Mesocletodes dorsiprocessus sp. nov., female v. A, antenna; B, P5; scale bars: 50 $\mu$ m. 


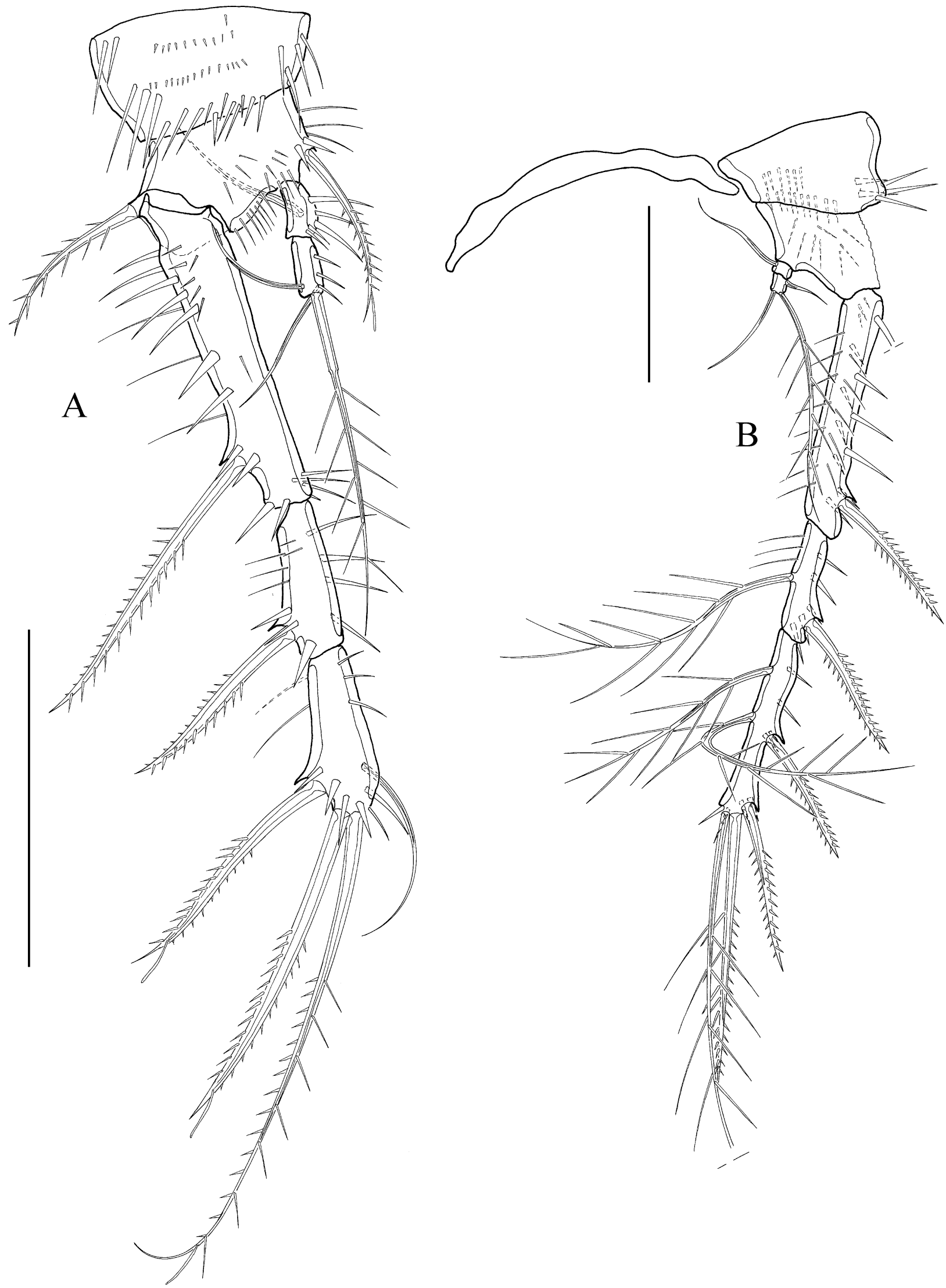

FIGURE 16: Mesocletodes dorsiprocessus sp. nov., female (holotype). A, P1; B, P2; scale bars: 50 $\mu \mathrm{m}$. 


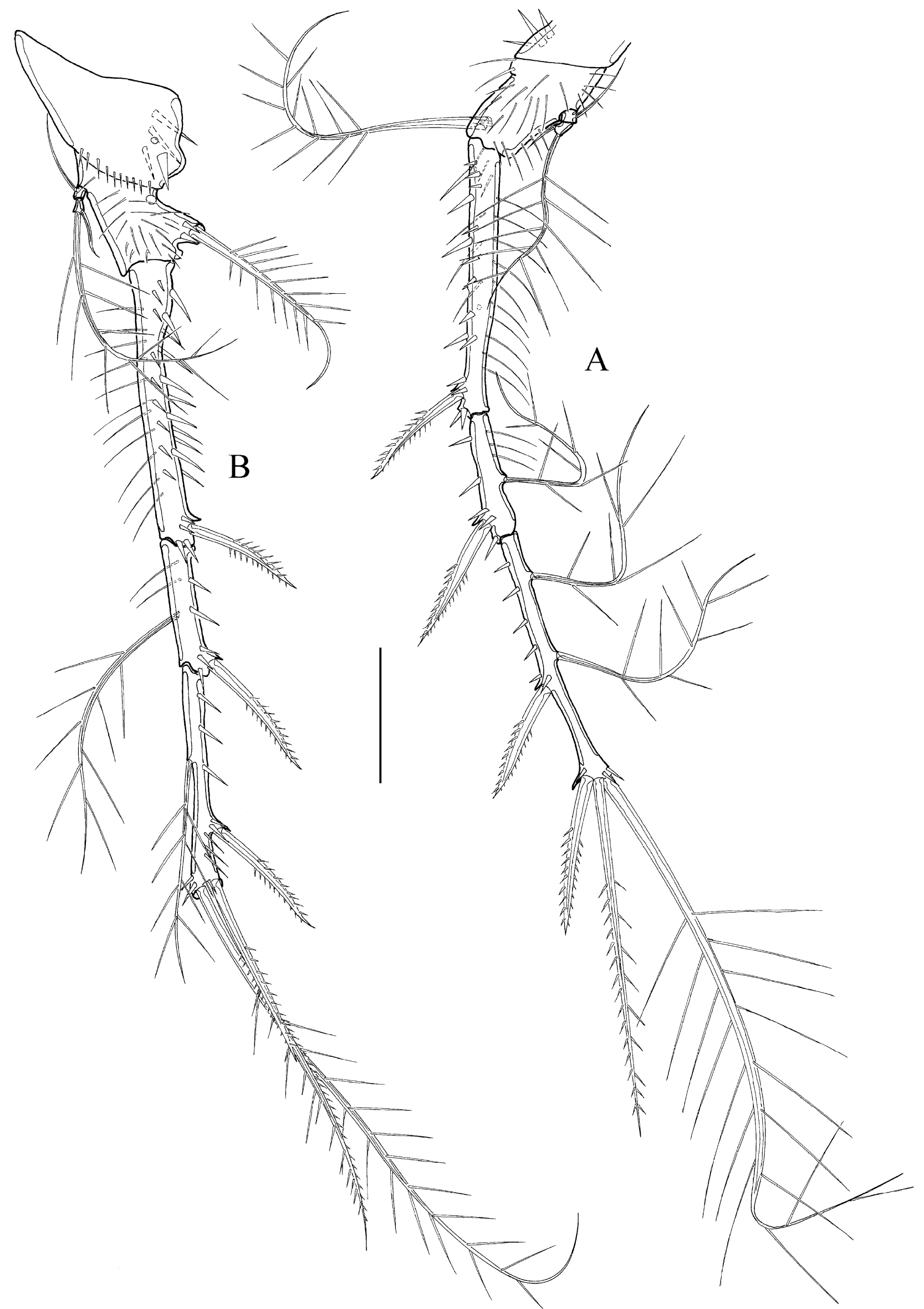

FIGURE 17: Mesocletodes dorsiprocessus sp. nov., female (holotype). A, P3; B, P4; scale bar: 50 $\mu \mathrm{m}$. 


\section{Mesocletodes meteorensis sp. nov.}

(Figs 18-24)

Etymology. The name refers to the RV "Meteor", on board of which the sample containing this species was taken.

Locus typicus: Angola Basin, (off Angola), RV „Meteor“, Cruise M-48/1, 27.07.2000.

Holotype: 1 female, dissected, mounted on 7 slides, coll. no. SMF 31424/1-7; at station 346/1 (16 $17.0^{\circ}$ 'S / $05^{\circ} 27.0^{\prime} \mathrm{E}, 5389 \mathrm{~m}$ ).

Paratype: 1 female, dissected, mounted on 10 slides, coll. no SMF 31425/1-10 at station 346/3 (16 $\left.17.0^{\circ} \mathrm{S} / 05^{\circ} 27.0^{\prime} \mathrm{E}, 5389 \mathrm{~m}\right)$.

Description of female. Habitus (Fig. 18) of cylindrical shape, no clear distinction between prosome and urosome. Body length $627 \mu \mathrm{m}$. Rostrum small, not protruding, with 2 sensilla. Cphth with a dorsal cuticular process which is triangular, curved and pointing backwards. Process with several spinules. Cphth with several fine spinules. Distal margins of cphth and bodysomites with smooth hyaline frill. Long sensilla on distal margins of body somites, except the penultimate one. Spinules arranged in rows and decreasing in length posteriorly. Body blotched with small depressions (as depicted for telson). Genital double somite incompletely fused.

Telson square, dorsally with bifid cuticular process peaked backwards: robust at the insertion, anterior and posterior peaks short, of equal length. Caudal region of telson with several rows of spinules, lateral to the process 1 sensillum on each side.

A1 (Fig. 19A) 8-segmented, acrothek on segments 4 and 8. First segment without seta but with 2 rows of spinules. Second segment with a strong protrusion bearing a strong bipinnate seta. Spines of A1 with 1 STE each.

Setal formula: I:0, II:6, III:6, IV:2+Aes, V:1, VI:2, VII:4, VIII:6+Aes.

A2 (Fig. 19B) basis with fine spinules. Exp small, 1-segmented with 2 bipinnate setae of unequal length. Enp1 with few outer spinules. Enp2 covered by spinules, with 2 medial bipinnate spines with 1 STE each and 6 terminal elements. 1 outer bipinnate spine, 2 geniculated setae, 1 bipinnate seta, 1 bipinnate seta with STE, this seta fused to a small bare seta at the base.

Md (Figs 20E, F) gnathobase with broad grinding face and 3 rows of spinules. Grinding face composed of 1 imbricate, distally carved seta, beneath 1 bare, spoon like seta, followed by several fused toothlike elements. Strong bare seta ventrally. Palpus 2- segmented with spinules. Basis with 1 seta (seta lost during preparation). Enp 1- segmented, with 4 terminal and 1 subterminal setae. Exopodal lobe with 2 bipinnate setae.

Mxl (Figs 20B, C) arthrite of the praecoxa with long spinules and 10 armature elements: 2 bare surface setae (depicted beneath), 2 strong, tooth like setae with spinules, 1 strong, unarmed tooth like seta, 1 strong, undulated unipinnate seta, 1 brushlike seta, 1 compact, unipinnate seta, 1 slender, unipinnate seta, 1 strong, unipinnate seta. Coxa with long spinules and 5 setae, strongest seta brushlike, incompletely fused to coxa. Basis with 7 setae and several spinules.

Mx (Fig. 20A) syncoxa with 2 endites. Proximal endite with 1 bare seta, distal endite with 3 setae: 1 strongly bipinnate and 2 bare setae. Basis with 2 strongly bipinnate setae and 2 bare setae. Enp 1-segmented, very small, with 2 bipinnate setae.

Mxp (Fig. 20D) syncoxa with many fine spinules and 2 bipinnate setae of unequal length. Basis with fine outer and coarse inner spinules. Enp 1-segmented, fused to strong claw.

P1 (Fig. 21A) coxa with several spinules. Basis with 1 inner and 1 outer spine, net-like structure close to outer seta. Exp 3-segmented. Exp1 and 2 without inner armature. Exp3 proximally with inner tube pore, 3 bipinnate spines with 1 STE each and 1 bare inner seta. Enp biarticulate. Enp1 with inner seta. Enp2 with 1 terminal, bipinnate spine, 1 terminal, bipinnate seta and 1 bare, inner seta. Setal formula as in Table 4 .

P2-P4 (Figs 21B; 22A, B) coxae with several spinules, bases with outer seta and inner setular tufts, netlike structure close to outer seta. Exp 3-segmented, increasing in length and decreasing in breadth from P2 to P4. Exp1 with 5 (P3) or 4 (P4) fine, inner spinules. Exp1 without inner seta. Exp2 with inner, bipinnate seta 
and outer spine. Exp3 of P2 and P3 with 2 bipinnate, outer spines and 2 bipinnate setae terminally. P4 Exp3 with 2 outer, bipinnate spines, 1 terminal bipinnate and 1 inner, bipinnate seta. Second terminal seta probably lost during sample treatment. Enp biarticulate. Enp1 with inner bipinnate seta. P2-P4 Enp2 with 1 outer, 2 terminal and 1 inner setae. Spines with spinules at their insertion points. Setal formula as in Table 4.

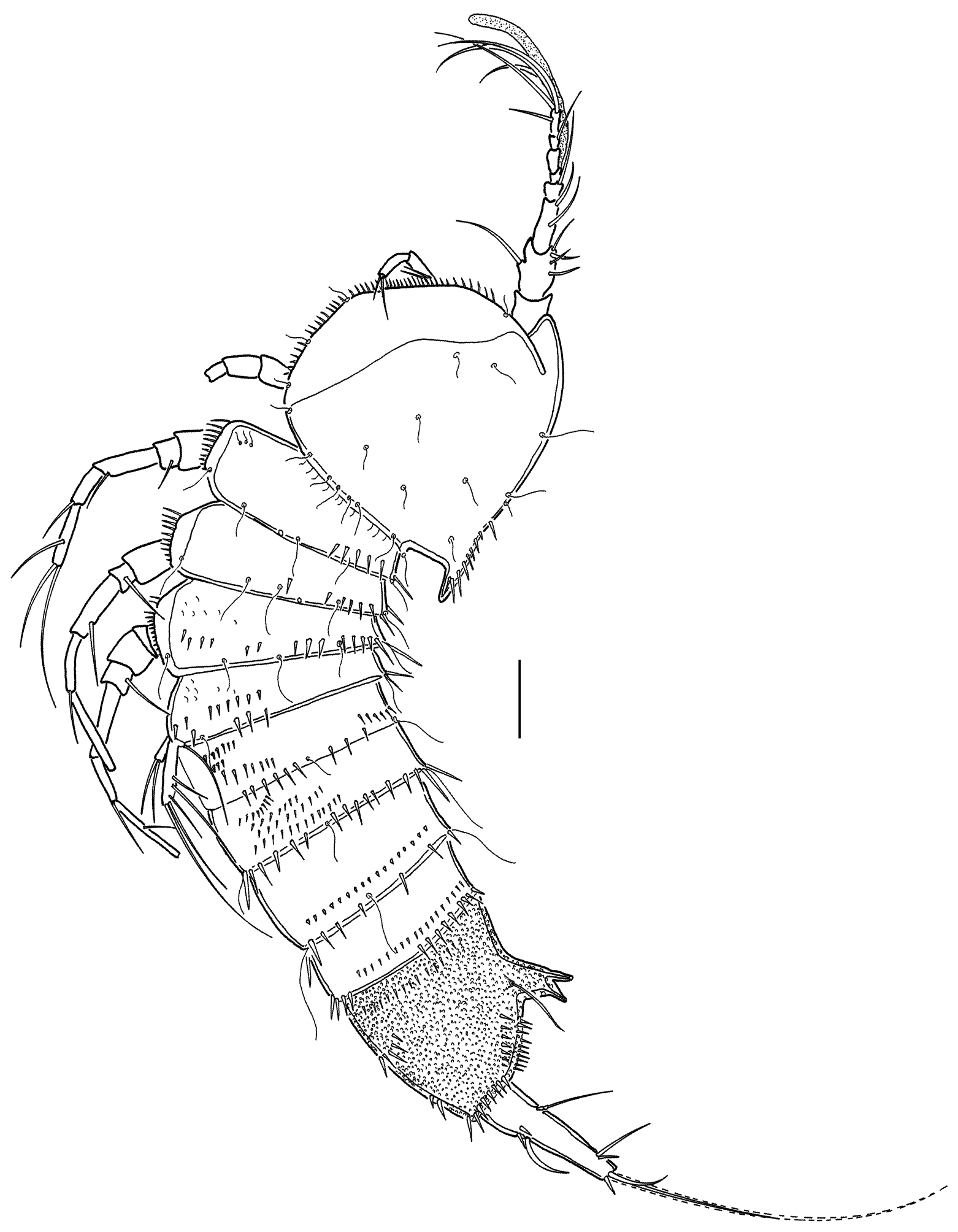

FIGURE 18: Mesocletodes meteorensis sp. nov., female (holotype). Habitus lateral view, with detail of overall surface structure illustrated on telson; scale bar: $50 \mu \mathrm{m}$. 


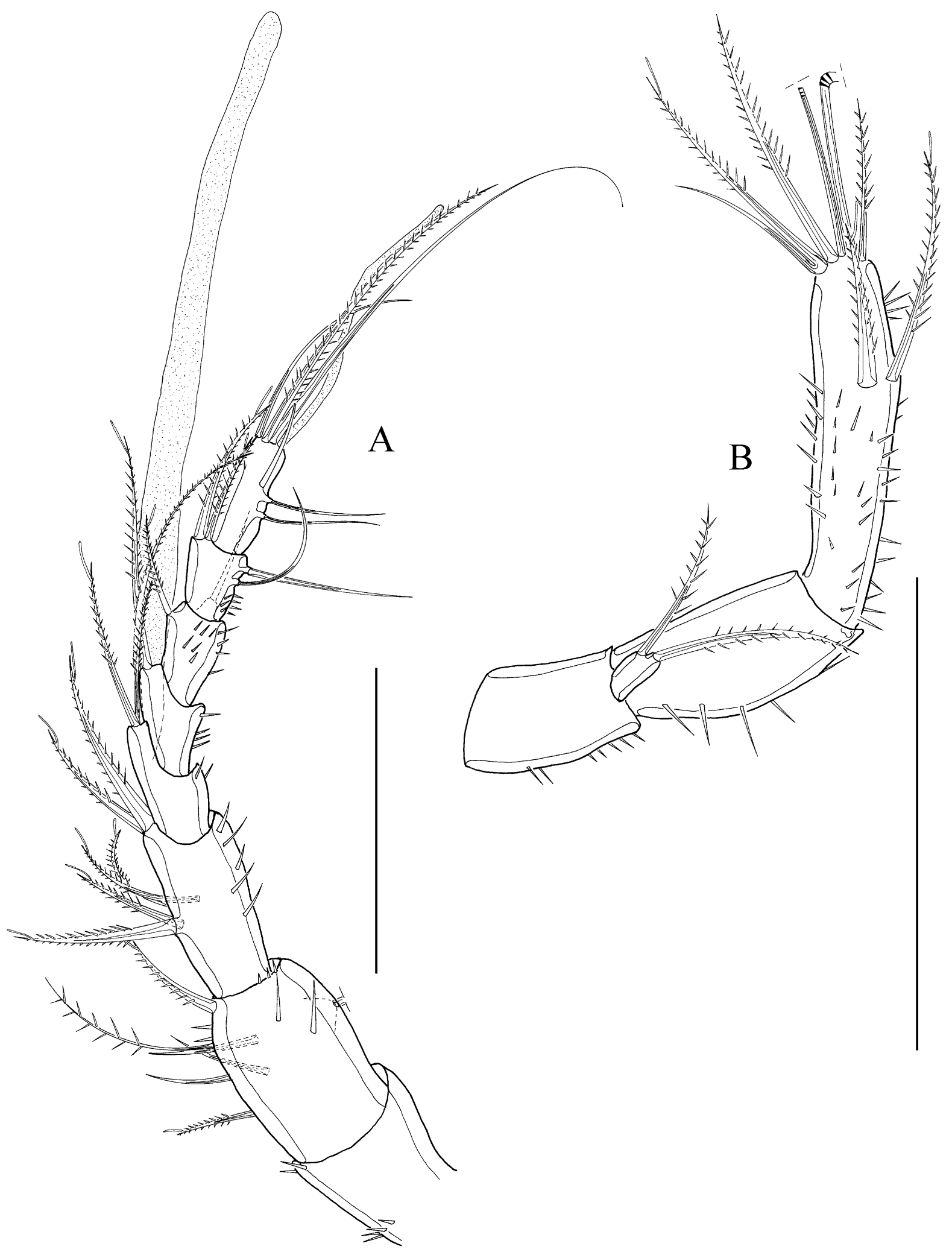

FIGURE 19: Mesocletodes meteorensis sp. nov., female (paratype). A, antennula ; B, antenna; scale bars: 50 $\mu \mathrm{m}$. 


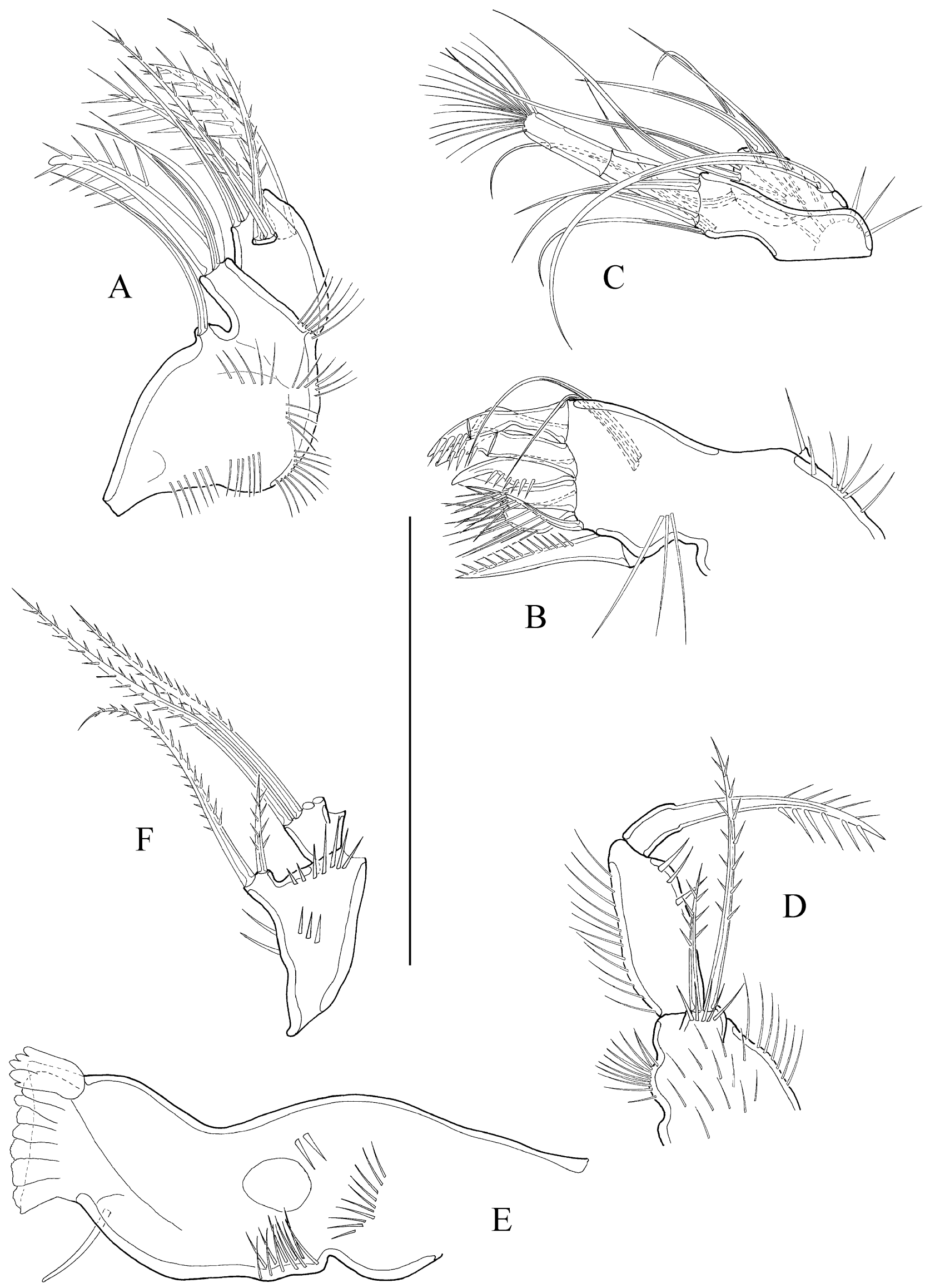

FIGURE 20: Mesocletodes meteorensis sp. nov., female (holotype). A, maxilla; B, maxillula; C, maxillular palpus; D, maxilliped; E, mandibula gnathobasis; F, mandibular palpus; scale bar: $50 \mu \mathrm{m}$. 


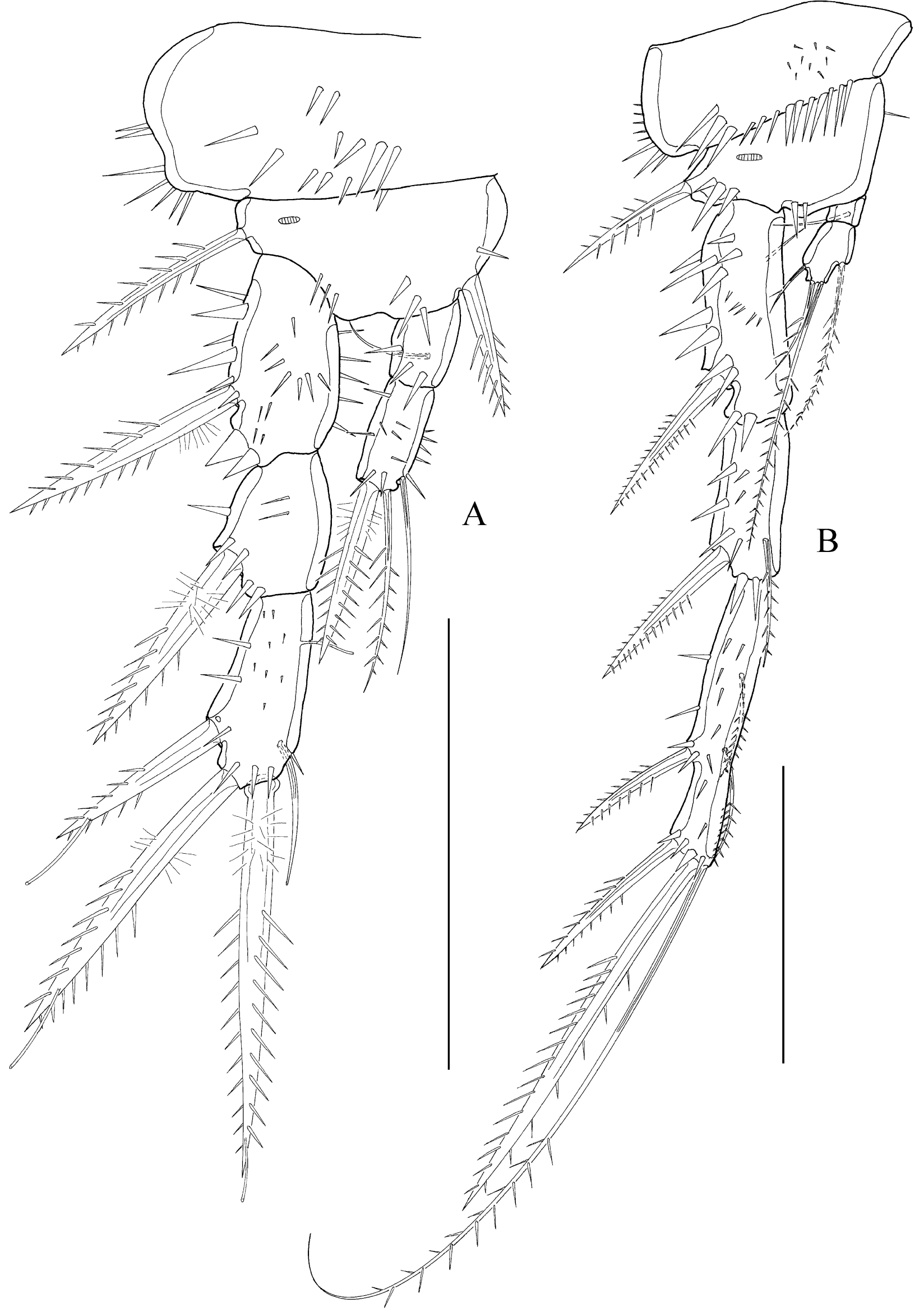

FIGURE 21: Mesocletodes meteorensis sp. nov., female (paratype). A, P1; B, P2; scale bars: 50 $\mu \mathrm{m}$. 


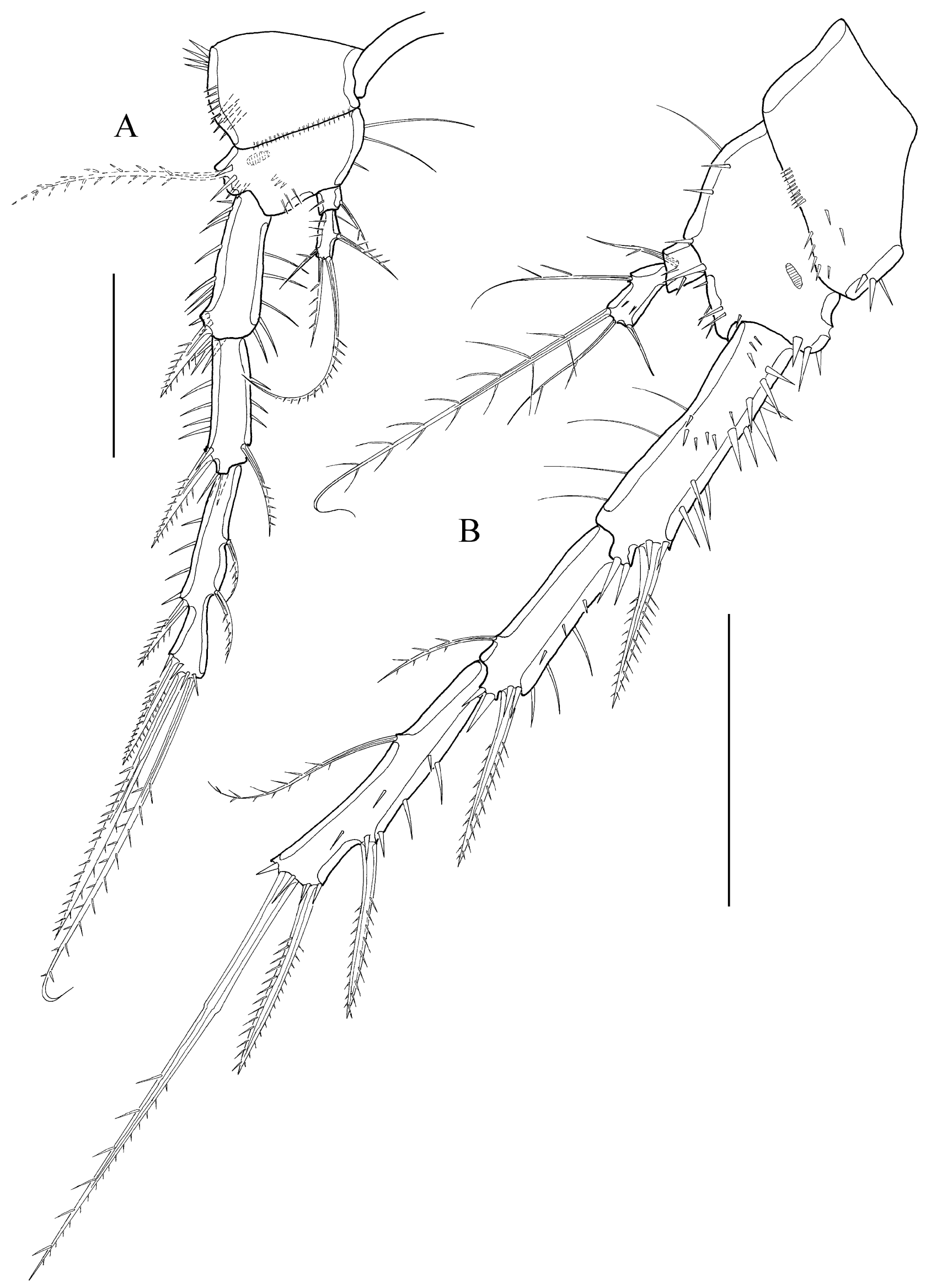

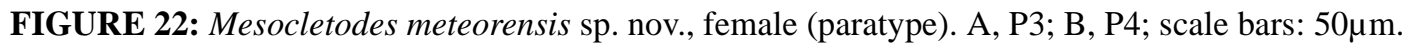




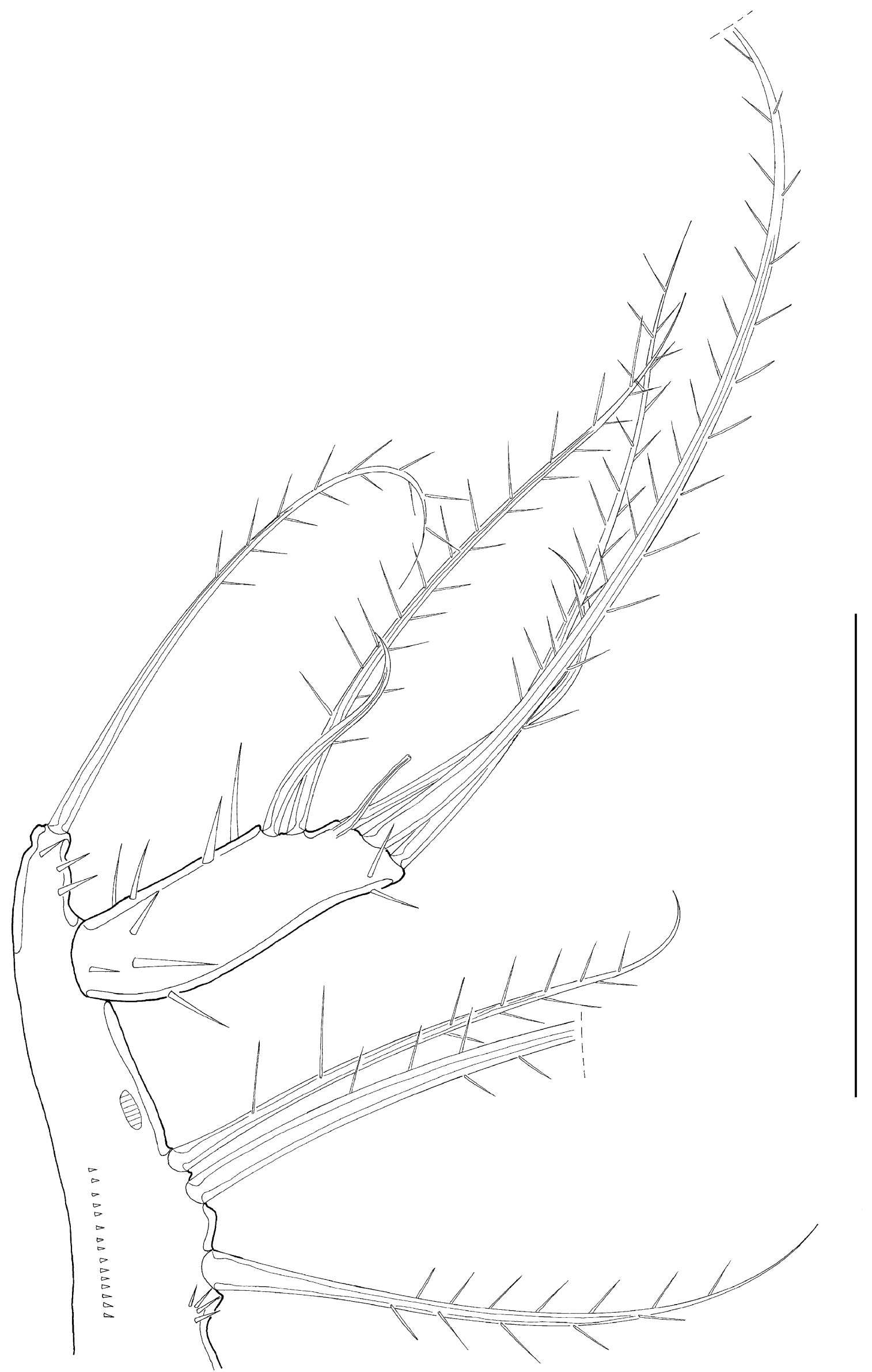

FIGURE 23: Mesocletodes meteorensis sp. nov., female (holotype). P5; scale bar: 50 $\mu \mathrm{m}$. 


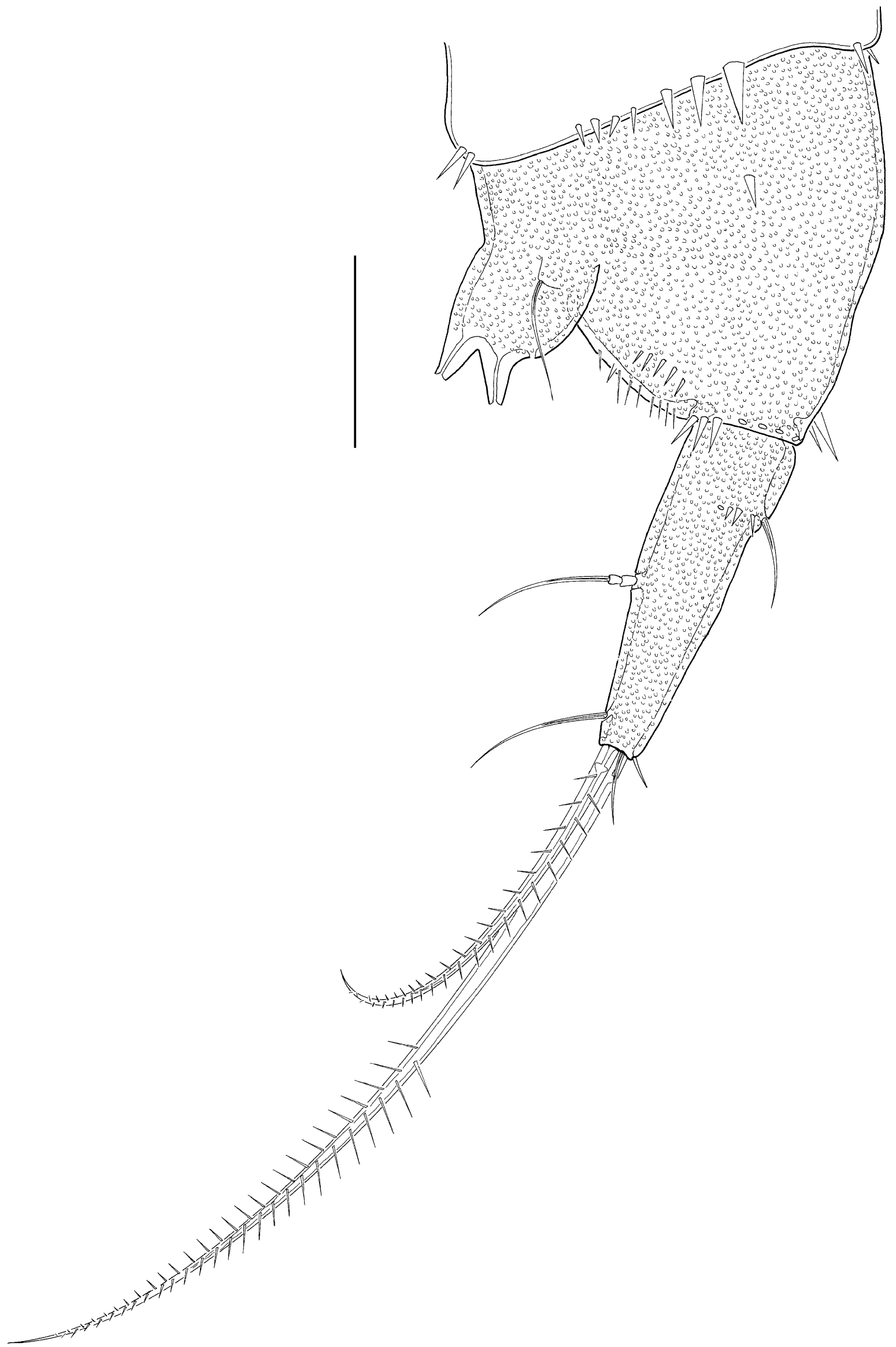

FIGURE 24: Mesocletodes meteorensis sp. nov., female (holotype). telson and furcal rami lateral view; scale bar: $50 \mu \mathrm{m}$. 


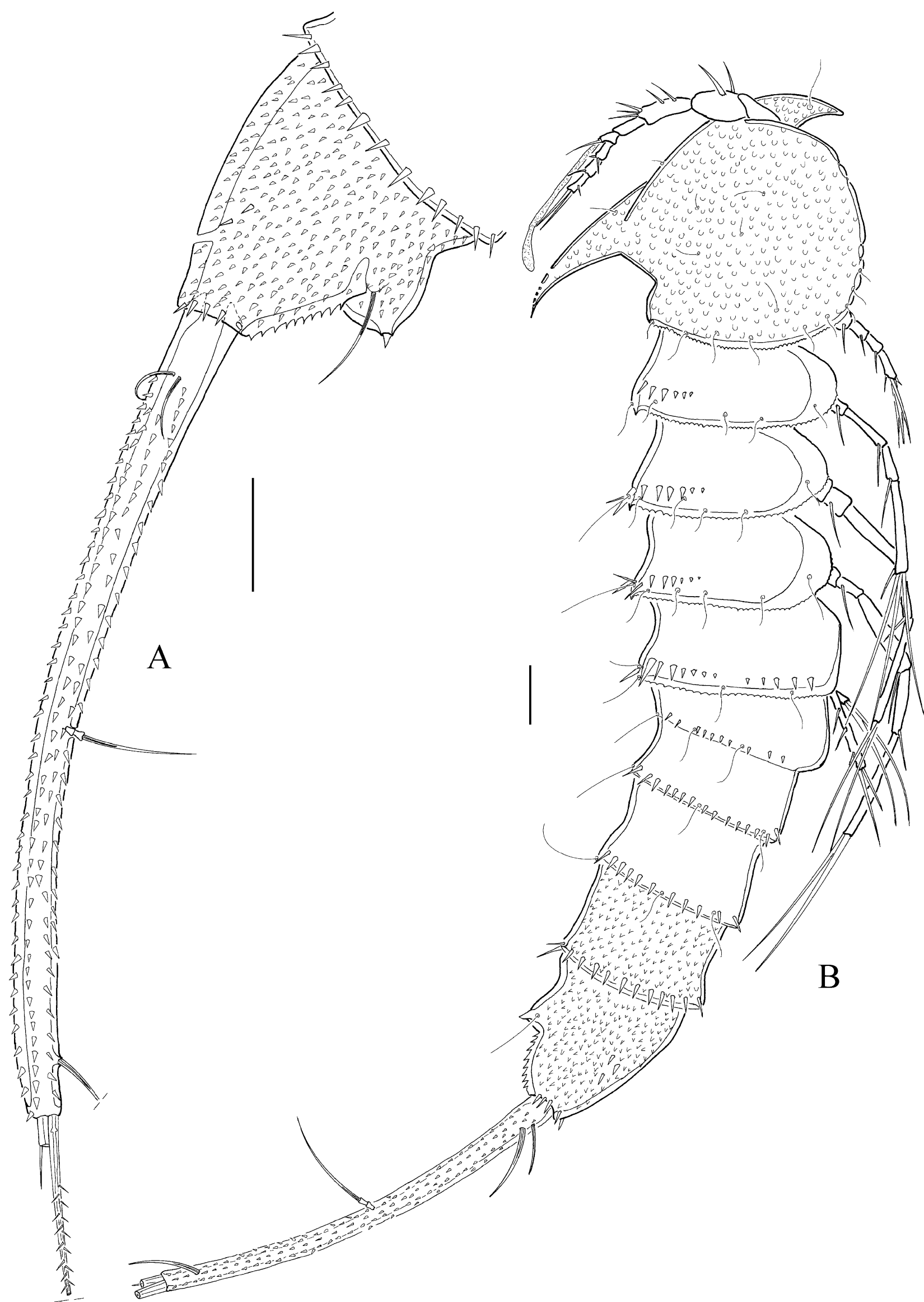

FIGURE 25: Mesocletodes robustus, female. A, telson and furcal rami lateral view; $\mathrm{B}$, habitus lateral view, with detail of surface structure of Cephalothorax and overall surface structure illustrated; scale bars: $50 \mu \mathrm{m}$. 
TABLE 4: Mesocletodes meteorensis sp. nov. setal formula of P1-P5.

\begin{tabular}{lll}
\hline & Exp & Enp \\
\hline P1 & I-0, I-0, I-2-1 & $0-1,0-$ I1-1 \\
P2 & I-0, I-1, II-2-2 & $0-1,1-2-1$ \\
P3 & I-0, I-1, II-2-2 & $0-1,1-2-1$ \\
P4 & I-0, I-1, II-2-1 & $0-1,1-2-1$ \\
P5 & $2-3-0$ & $1-1-1$ \\
\hline
\end{tabular}

P5 (Fig. 23) basenp with several spinules. Outer lobe of basenp with setophore bearing 3 spinules and 1 outer seta. Inner lobe not protruding, with 1 inner, 1 median and 1 outer seta. The outer and median seta are close to each other, the long inner seta separated from the former two elements. Exp approximately 3 times longer than broad, with 5 setae and 1 terminal tube pore. Exp sparsely covered with spinules. Net-like structure between outer and inner lobe of basenp. Setal formula as in Table 4.

Furcal rami (Fig. 24) approximately 3 times longer than wide (width measured at its base), insertion surrounded by spinules of anal somite. Furcal ramus with 7 setae: setae I and II ventral and lateral accompanied by 1 spinule each close to the insertion, seta III dorsally subterminal, setae IV and V terminal, seta VI ventrally terminal, seta VII in the middle of furcal ramus. Setae I, II, III, VI are bare, seta IV long and bipinnate, seta V short and bipinnate, seta VII triarticulate and bare.

Male unknown.

\section{Redescription of Mesocletodes robustus Por, 1965}

(Figs 25-30)

\section{Type material (used for comparison):}

Paratype: 1 female dissected, mounted on 2 slides, coll. no. Cop52 1-2, Hebrew University of Jerusalem, Israel

Redescription is based on collected material: Angola Basin, 27.07.2000. 1 female, dissected, mounted on 6 slides, coll. no. SMF 31422/1-6 at station 346/1 (16 $\left.17.0^{\prime} \mathrm{S} / 05^{\circ} 27.0^{\prime} \mathrm{E}, 5389 \mathrm{~m}\right), 1$ female, dissected, mounted on 7 slides, coll. no. SMF 31423/1-7 at station 346/7 (16 $\left.{ }^{\circ} 17.0^{\prime} \mathrm{S} / 05^{\circ} 27.0^{\prime} \mathrm{E}, 5389 \mathrm{~m}\right), 1$ female mounted on 1 slide, coll. no. SMF $31435 / 1$ at station 346/6 (16 $\left.17.0^{\prime} \mathrm{S} / 05^{\circ} 27.0^{\prime} \mathrm{E}, 5389 \mathrm{~m}\right)$.

Description of female. Habitus (Figs 25B) of cylindrical shape, no clear distinction between prosome and urosome. Body length $1327 \mu \mathrm{m}$. Rostrum tipped, slightly protruding, with 2 sensilla. Cphth blotched as depicted, with several setules and with dorsal triangular cuticular process, which is curved and points in a posterior direction. Process with 4 distal apertures. Distal margins of cphth and prosomites with denticulated hyaline frill, urosomites with bare hyaline frill. Long sensilla on distal margins of body somites, except the penultimate one. P2-P4 bearing body somites dorsally with rows of spinules, P5-bearing somite and urosomites with additional lateral rows of spinules. Telson square, with dorsal cuticular process peaking in a small spine (like M. abyssicola), 1 sensillum on each side of the process. Somites covered by spinules. Genital double-somite incompletely fused. P2-P4 bearing body somites with thickened cuticula at the insertions of legs.

A1 (Fig. 26A) 8-segmented, acrothek on segments 4 and 8. First segment without setae, proximally and medially with 1 row each of spinules. Second segment with a strong protrusion bearing a strong, bipinnate seta. Spines of A1 with 1 STE each.

Setal formula: I:0, II:8, III:6, IV:3+Aes, V:1, VI:2, VII:3, VIII:7 +Aes.

A2 (Fig. 26B) basis with spinules. Exp 1-segmented with 2 bipinnate setae of unequal length. Enp1 with corona of spinules. Enp2 with long, outer spinules, 2 bipinnate, medial spines with 1 STE each and 6 terminal elements. 1 outer unequal bipinnate spine, 3 geniculated, coarse bipinnate setae, 1 annulated, bipinnate seta fused to 1 fine, unipinnate inner seta at its base. Enp2 with terminal spinules of different length. 

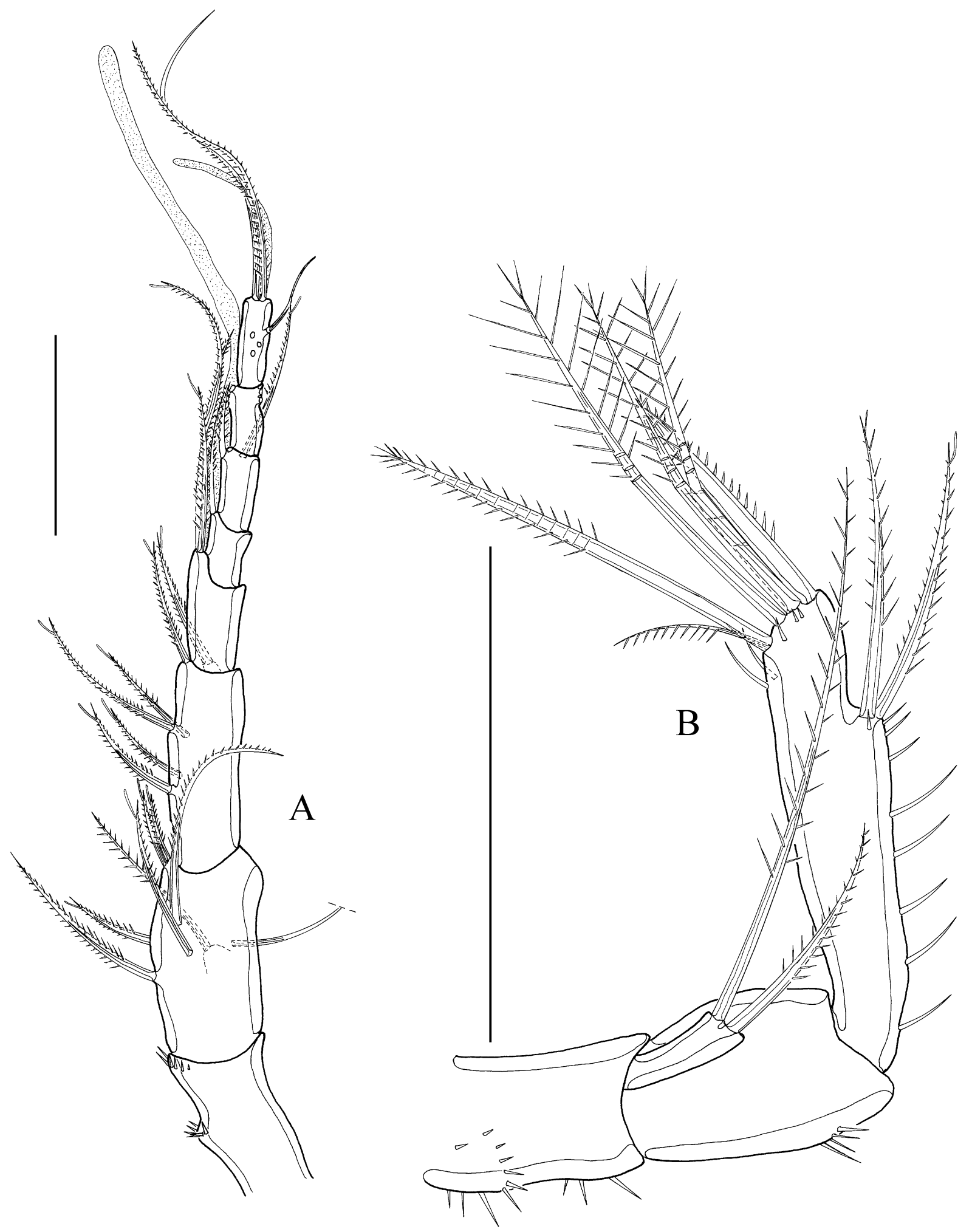

FIGURE 26: Mesocletodes robustus, female. A, antennula; B, antenna; scale bars: $50 \mu \mathrm{m}$.

Md lost during preparation.

Mxl (Fig. 27A) arthrite of the praecoxa with 10 armature elements: 2 surface setae (depicted beneath). 2 toothlike setae with strong terminal spinules, 1 undulated, tooth like seta with strong spinules terminally, 2 brushlike setae, 1 depressed, swung, unipinnate seta, 1 unipinnate seta on a protrusion, 1 single, unipinnate 
seta, very long spinules on the surface (depicted beneath). Coxal endite with 5 setae, incompletely fused to pinnate terminal seta. Corona of spinules at the base of coxal endite. Basis with 7 setae, segments of enp and exp not expressed.

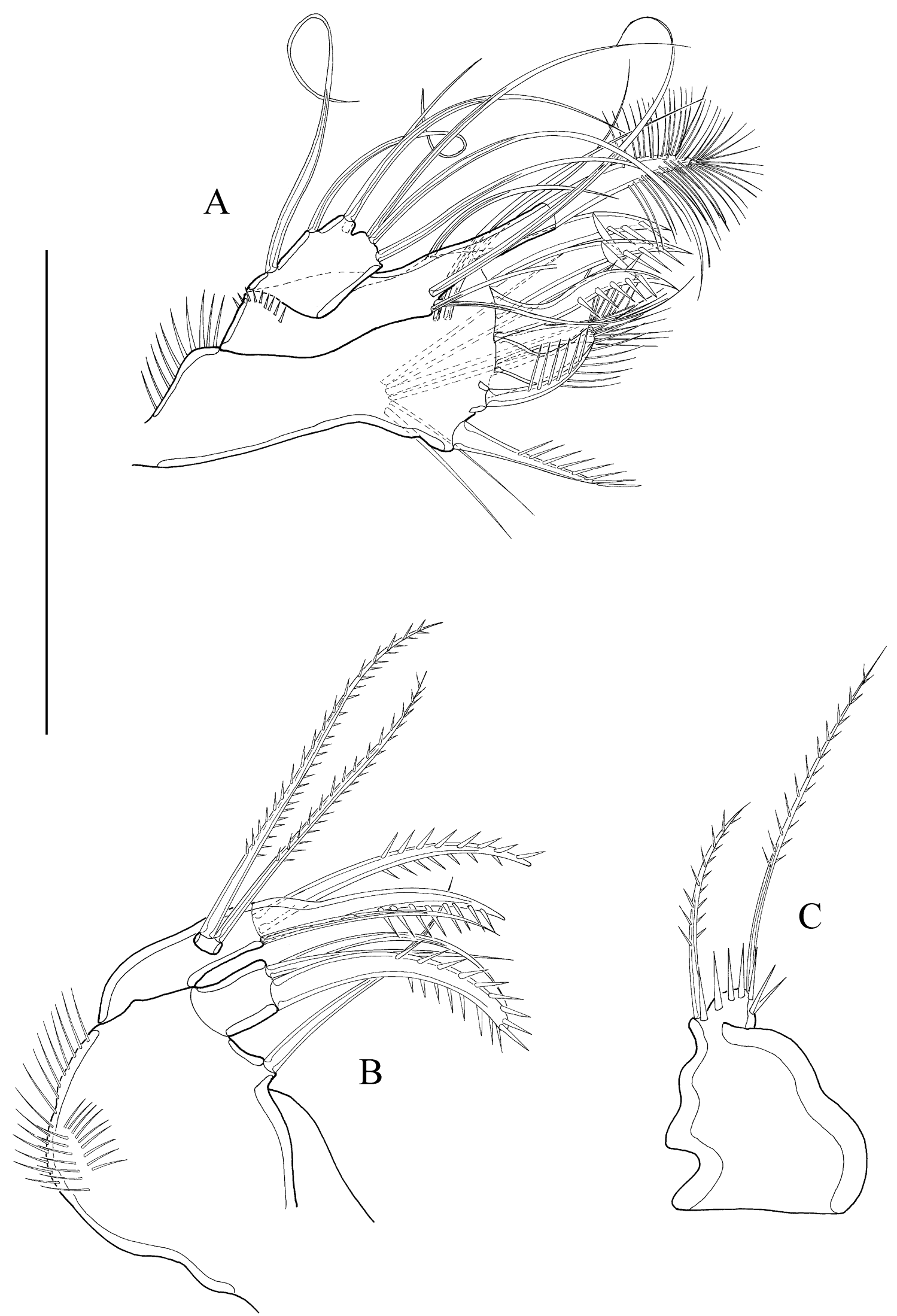

FIGURE 27: Mesocletodes robustus, female. A, maxillula; B, maxilla; C, syncoxa of maxilliped; scale bar: 50 $\mu \mathrm{m}$. 

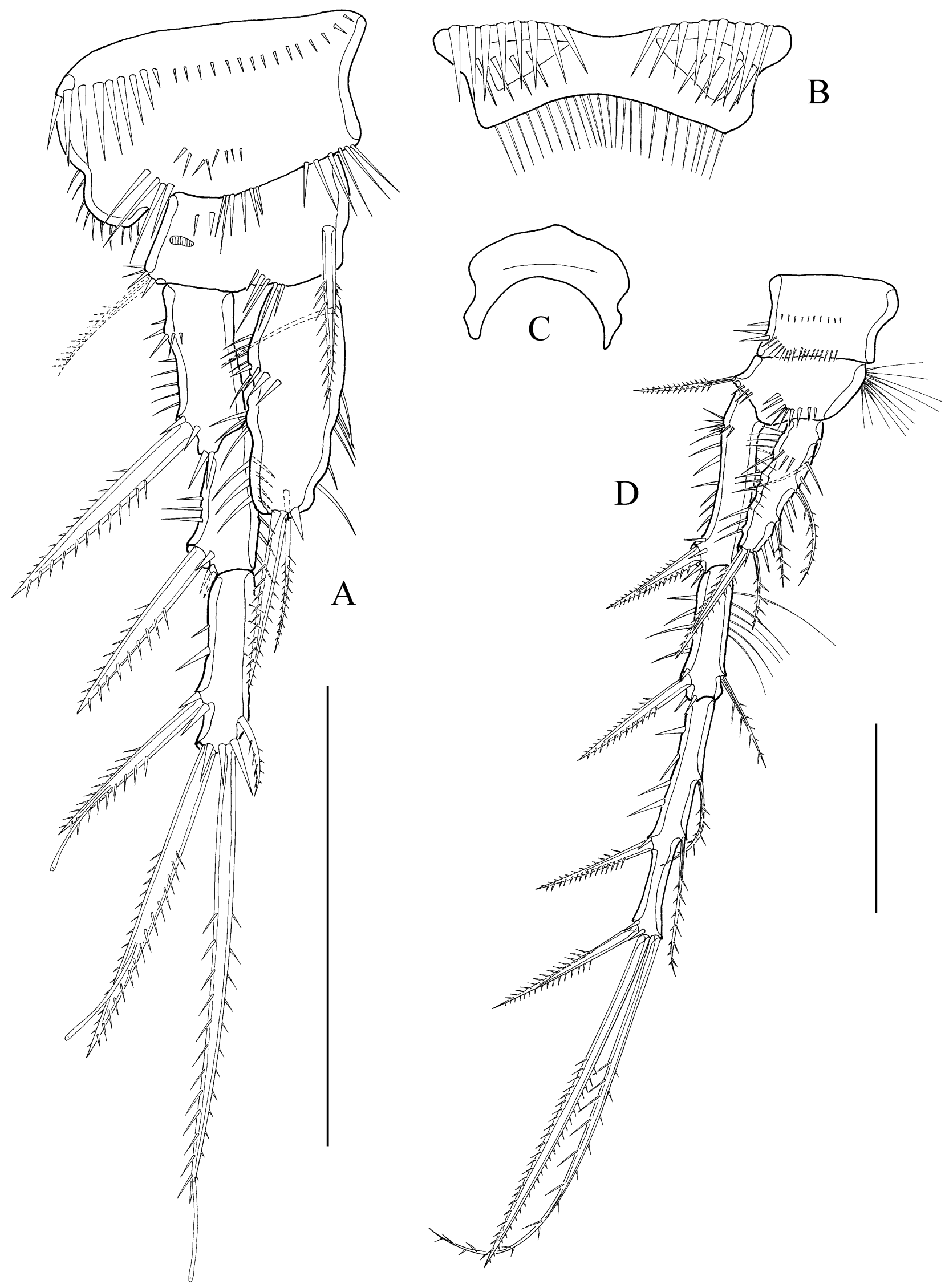

FIGURE 28: Mesocletodes robustus, female. A, P1; B, P1 intercoxal sclerite; C, P2 intercoxal sclerite; D, P2; scale bars: $50 \mu \mathrm{m}$. 


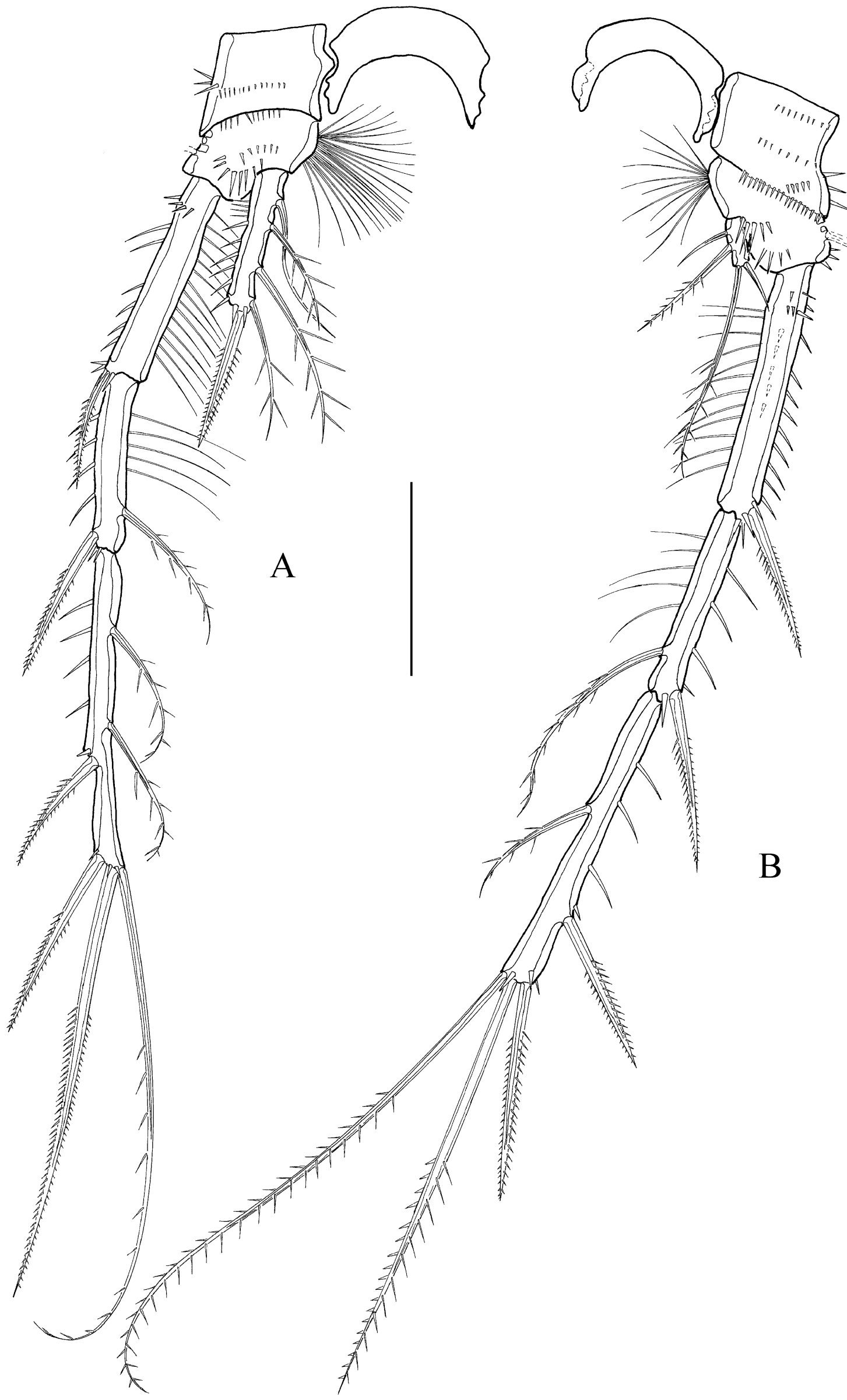

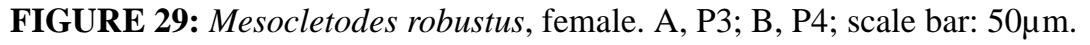




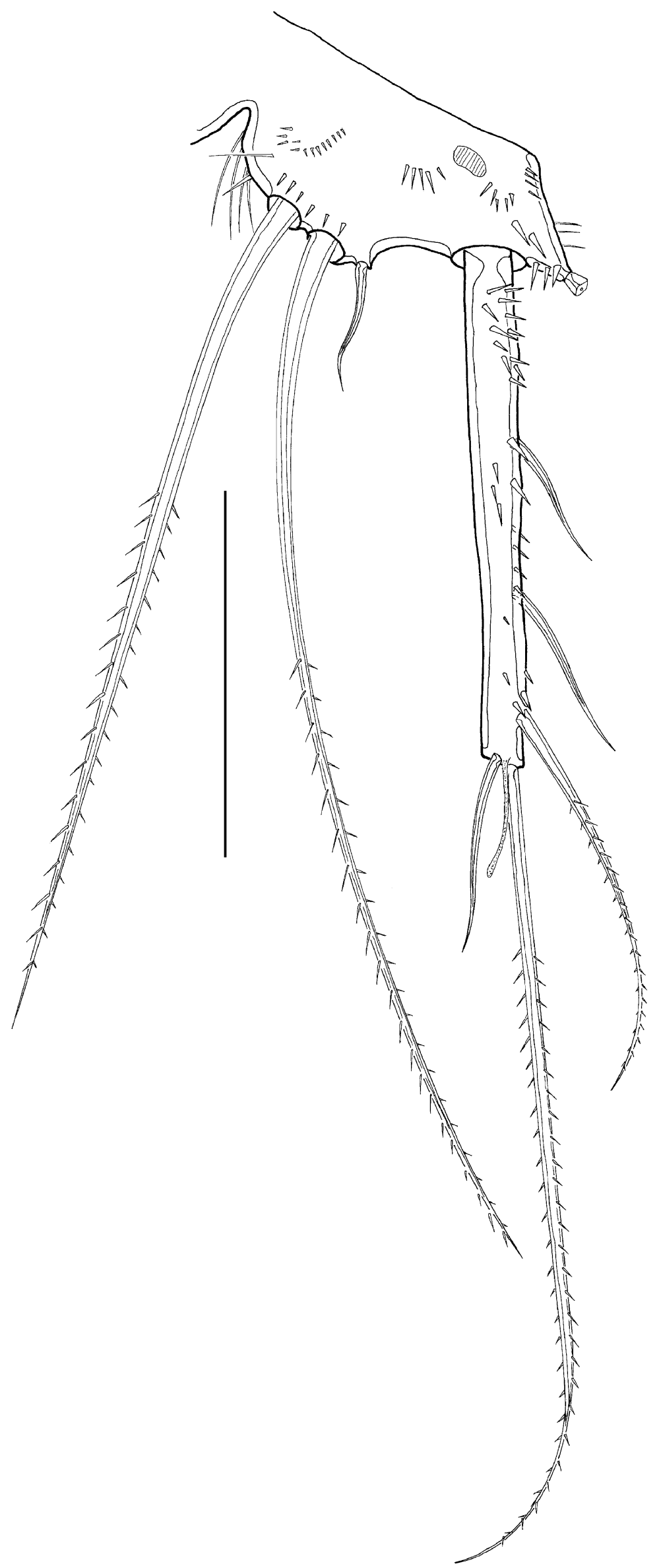

FIGURE 30: Mesocletodes robustus, female. P5; scale bar: 50 $\mu \mathrm{m}$. 
Mx (Fig. 27B) syncoxa with several rows of spinules and 2 endites. Proximal endite with 1 bare seta, distal endite with 3 setae: 1 strongly bipinnate and 2 bare setae. Basis with 3 setae: 2 pinnate setae, incompletely fused to basis and 1 bare seta. Enp small, 1-segmented, with 2 long, bipinnate setae.

Mxp (Fig. 27C) syncoxa with 2 long, bipinnate setae. Enp 1 segmented and fused to strong claw. Basis and enp lost during dissection.

P1 (Fig. 28A) coxa with several spinules. Basis with 1 inner and 1 outer spine, net-like structure close to the insertion of outer seta. Exp 3-segmented. Exp1 and exp2 without inner armature. Exp3 with 1 outer and 2 terminal, bipinnate spines with distal tube pores and 1 short bipinnate inner seta. Enp 1-segmented, extremely long and broad. Enp with 1 bare inner seta, 1 bipinnate, terminal seta and 1 bipinnate, terminal spine. Intercoxal sclerite (Fig. 27B) with 2 triangular holes, covered with many long strong spinules. Setal formula as in Table 5.

P2-P4 (Figs 28C, D; 29A, B) coxae with several spinules. Bases with outer seta and inner setular tufts. Net-like structure close to the outer seta of P2, P3 and P4 with a lateral porus. Exp 3- segmented, increasing in length posteriorly. Exp1 without inner armature, but with inner spinules. Exp2 with inner seta and 5 long, inner spinules. Exp3 with 2 bipinnate outer spines, 1 bipinnate, terminal spine, 1 bipinnate seta terminally and 2 (P2 and P3) or 1 (P4) inner, bipinnate setae. P2-P4 Enp 1-segmented, decreasing in length and broadness posteriorly. Enp with 1 bare seta, 3 bipinnate setae and 1 bipinnate spine (P2 and P3) or 2 bare and 2 bipinnate setae (P4). All spines with spinules close to their insertions. Intercoxal sclerites as depicted for P2. Setal formula as in Table 5.

TABLE 5: Mesocletodes robustus setal formula of P1-P5.

\begin{tabular}{lll}
\hline & Exp & Enp \\
\hline P1 & I-0, I-0, I-2-1 & $0-\mathrm{I} 1-1$ \\
P2 & I-0, I-1, II-2-2 & $0-\mathrm{I} 1-3$ \\
P3 & I-0, I-1, II-2-2 & $0-\mathrm{I} 1-3$ \\
P4 & I-0, I-1, II-2-1 & $0-2-2$ \\
P5 & $3-2-0$ & $1-1-1$ \\
\hline
\end{tabular}

P5 (Fig. 30) outer lobe of basenp with spinules and setophore. Inner lobe of basenp barely protruding, with inner setular tuft, spinules and 1 long inner seta, 1 long, median seta and one short, outer seta. The outer and median seta are close to each other, the long, inner seta separated from the former two elements. Net-like structure close to exp insertion. Exp approximately 9 times longer than broad, with 5 setae and 1 terminal tube pore. Exp covered by spinules, especially in the proximal part. Setal formula as in Table 5.

Furcal rami (Fig. 25A) approximately 13 times longer than broad (the widest part measured at its base), the insertion surrounded by spinules of anal somite. Furcal ramus with spinules and 7 setae: I and II close to the beginning (ventral and lateral) III subdistally, IV and V terminally, VI ventrally terminal, VII in the middle of furcal ramus. Setae I, II, III, VI are bare, IV lost during sample treatment, V bipinnate (lost during preparation) VII triarticulate and bare.

Male unknown.

\section{Discussion}

\section{Historical background}

Due to their body shapes, Mesocletodes monensis (Thompson, 1893), M. irrasus (Scott, 1894) and M. abyssicola (T. \& A. Scott, 1901) were originally attributed to the genus Cletodes Brady, 1872. Sars (1909) redescribed Cletodes irrasus as Mesocletodes irrasus and erected the taxon Mesocletodes. Twelve years later, 
Sars (1921) redescribed C. monensis as M. monensis and C. abyssicola as M. abyssicola and presented the description of Mesocletodes inermis Sars, 1921.

When the genus Mesocletodes was erected, it could clearly be separated from Cletodes and most of the Cletodidae T. Scott, 1904, but at first remained part of this obviously heterogeneous family (Lang 1936b; Por 1979).

Several decades later, Por (1986) revised the Cletodidae and erected, among other taxa, the Argestidae, which nowadays refer the genera Actinocletodes Fiers, 1986, Argestigens Willey, 1935, Argestoides Huys \& Conroy-Dalton, 1997, Austrocletodes Pallares 1979, Bodinia George, 2004, Pontocletodes Apostolov, 1980, Rosacletodes Wells, 1985, Argestes Sars, 1910, Corallicletodes Soyer, 1966, Dizahavia Por, 1979, Eurycletodes Sars, 1909, Fultonia T. Scott, 1902, Hemicletodes Lang, 1936, Hypalocletodes Por, 1967, Leptocletodes Sars, 1921, Megistocletodes Por, 1986, Neoargestes Drzycimski, 1967, Odiliacletodes Soyer, 1964, Parargestes Lang, 1948. The former seven genera were considered as incertae sedis (Bodin 1997; George 2004).

\section{Allocation of the new species into Mesocletodes}

The 4 new species described here (Mesocletodes angolaensis sp. nov., M. bicornis sp. nov., M. dorsiprocessus sp. nov., M. meteorensis sp. nov.) and M. robustus are clearly affiliated to the taxon Mesocletodes. Some characters included in the amended generic diagnosis are considered as synapomorphies [plesiomorphic states in square brackets]:

1) Second antennular segment with strong protrusion bearing 1 strong, bipinnate seta pointing backwards [no protrusion, corresponding seta of normal shape];

2) P1 exp3 proximal, outer spine reduced [proximal outer spine well developed];

3) P1 exp3 spines with Subapical Tubulate Extensions [no Subapical Tubulate Extensions]

4) Md gnathobase forming a strong, grinding tooth [gnathobase of normal shape].

Character 1: Second antennular segment with strong protrusion bearing 1 strong, bipinnate seta which points backwards:

The presence of a protrusion arising from the outer margin of the segment, almost at right angles and bearing 1 strong, bipinnate seta pointing backwards is unique within the Argestidae and therefore considered as autapomorphic character for Mesocletodes.

Character 2: P1 exp3 proximal outer spine reduced:

Most Argestidae possess 5 setal elements on P1 exp3, whereas in Mesocletodes the proximal spine is missing. This condition is not the case for M. arenicola Noodt, 1952. However, the allocation of this species into Mesocletodes is also questionable due to other characters (i.e. the shape and armature of the furcal rami and the inner setation of pereiopodal exp). Some members of the genus Eurycletodes also lack the proximal spine, but only in combination with the expression of an inner seta in P1 exp2. Moreover, the reduction of single elements often occurs within the Harpacticoida. As Mesocletodes and Eurycletodes are quite well separated by additional apomorphies, the lack of the proximal spine in P1 exp3 is regarded as autapomorphic for Mesocletodes (and consequently also for Eurycletodes).

Character 3: P1 exp3 spines with Subapical Tubulate Extensions (STE):

Investigation of the herein described species of Mesocletodes and several type specimens of this genus revealed them all to possess STEs in spines of appendages, as described by Huys (1996) for Superornatiremidae. Such structures are not mentioned in literature for Argestidae with one exception: George (2008) described such STEs in the outer elements of P1 exp3 in Argestes angolaensis George, 2008 and Argestes mollis Sars, 1910. Although the presence of STEs in the rather primitive Argestes may indicate their plesiomorphic condition in Mesocletodes, we believe that their presence in the latter constitutes a derived stage, because in the remaining Argestidae no STEs have been detected so far. This points to convergent development in both Argestes and Mesocletodes rather than to secondary loss in all the remaining Argestidae. 
Therefore, STEs in the outer elements of P1 exp3 are considered as synapomorphic for all Mesocletodes species.

Character 4: mandibular gnathobase forming a strong grinding tooth:

The mandibular gnathobase of all members of the genus Mesocletodes takes the form of a unique and strongly derived strong grinding tooth. The gnathobases of some other Argestidae appear to be similar (e.g. Corallicletodes, Neoargestes, Fultonia and Megistocletodes), but preliminary observations show differences in the structure of the gnathobases between Mesocletodes and other Argestidae. Future investigations may resolve this.

The interpretation of the endopodal segmentation and setation of swimming legs P1-P4 in Mesocletodes are problematic so far, as it requires homologization of endopodal segments and setae within this genus and further within the Argestidae, which is still outstanding. Thus, the specific differences regarding the enps of the swimming legs have to be considered as diagnostic only.

\section{Phylogenetic status of the Mesocletodes abyssicola-group}

Comparison of all 14 species within the Mesocletodes abyssicola-group, including the new species described here, reveals at least 3 synapomorphies [plesiomorphic states in square brackets]:

5) Cuticular process dorsally on cphth [no dorsal process developed];

6) Cuticular process dorsally on telson [no dorsal process developed];

7) Furcal rami remarkably elongated between seta III and VII [no remarkably elongate furcal rami].

Characters 5 and 6: Cuticular processes dorsally on cphth and telson:

Within the Argestidae, only members of the rather derived taxon Mesocletodes show the named processes, while they are absent in all the remaining Argestidae. As the presence of cuticular body processes is quite uncommon, even in Harpacticoida, and not part of harpacticoid nor argestid ground-pattern, it has to be regarded as derived. Furthermore, we conclude that the presence of such processes, which always occur in the same position, shows it is more plausible as a derived synapomorphic condition in all corresponding species than the alternative of their secondary loss in all remaining members of Mesocletodes.

Character 7: Furcal rami remarkably elongated between seta III and VII:

All associates of Mesocletodes possess furcal rami which are longer than wide, with setae more or less evenly distributed over the whole ramus: setae IV, V and VI are always located terminally, setae I, II, III and VII are positioned closer to or in the proximal part of the ramus. Within Mesocletodes, an extreme elongation of furcal rami is observable in the members of the Mesocletodes abyssicola-group, always resulting from the increased distance between setae III and VII.

Two of the new species described here, Mesocletodes angolaensis sp. nov. and M. meteorensis sp. nov. deviate from the above defined apomorphies regarding characters 6 and 7. M. angolaensis sp. nov. lacks the dorsal cephalothoracic process, while M. meteorensis sp. nov. has relatively short furcal rami. Future detailed comparison may show whether these deviations reflect secondary reductions.

Based on morphological characters, the four new species are clearly differentiated from the known species.

Mesocletodes angolaensis sp. nov. resembles M. fladensis Wells, 1965, but differs in the following characters (Tab. 6). The clearest difference between these two species is visible when investigating the habitus: in contrast to $M$. fladensis, $M$. angolaensis sp. nov. possesses a cuticular process on the telson; three additional characters also differ. The atrophy of mouthparts observed in both species is difficult to interprete. Atrophied mouthparts have been sporadically described from other harpacticoid families such as the Aegisthidae Giesbrecht, 1892 and Pseudotachidiinae Lang, 1936 (Willen 2005). This suggests convergent adaptation to scarce availability of food in the deep sea. But since the males of some Argestidae, presumably less derived than Mesocletodes, such as Argestes, Argestoides and Bodinia, possess strong mouthparts (George 2004; Huys \& Conroy-Dalton 1997; Itô 1983), the loss of feeding appendages might support a 
monophylum of derived Argestidae as is assumed for Aegisthidae (Lee \& Huys 2000). For clarification, the extent of sexual dimorphism within the derived Argestidae needs to be the subject of future investigations.

TABLE 6: Morphological differences between M. angolaensis sp. nov. and M. fladensis.

\begin{tabular}{lcc}
\hline & M. angolaensis sp. nov. & M. fladensis \\
\hline cuticular process on telson & present & absent \\
number of antennular segments & 7 & 8 \\
antenna & basis & allobasis \\
furcal rami & elongated & less elongated \\
\hline
\end{tabular}

Mesocletodes meteorensis sp. nov. might easily be confused with M. brevifurca Lang, 1936. However, comparison with the type material of the latter species showed clear differences, justifying M. meteorensis sp. nov. as a new species (Tab. 7).

TABLE 7: Morphological differences between M. meteorensis sp. nov. and M. brevifurca.

\begin{tabular}{lcc}
\hline & M. meteorensis sp. nov. & M. brevifurca \\
\hline $\begin{array}{l}\text { cuticular cephalothoracic process } \\
\text { cuticular process on telson }\end{array}$ & with spinules & without spinules \\
P5 $\operatorname{~xp}$ & tips of equal length & tips of unequal length \\
& broader, with few strong spinules & $\begin{array}{c}\text { more slender, with many fine } \\
\text { spinules }\end{array}$ \\
\hline
\end{tabular}

Mesocletodes bicornis sp. nov. and M. dorsiprocessus sp. nov. have peculiar bifid dorsal processes on P3-P5 bearing somites and the first urosomite, which have not been described from any other species within Mesocletodes. These processes are of equal shape and size and are always present in the same position. Due to this, a high phylogenetic value of these bifid processes establishing a monophylum, is very plausible. Some differences in other characters were observed (Tab. 8). These distinctions justify M. bicornis sp. nov. and M. dorsiprocessus sp. nov. as different species but do not reject the monophyly of bifid dorsal process bearing species.

TABLE 8: Morphological differences between M. bicornis sp. nov. and M. dorsiprocessus sp. nov.

\begin{tabular}{lcc}
\hline & M. bicornis sp. nov. & M. dorsiprocessus sp. nov. \\
\hline cuticular cephalothoracic process & double & single \\
P5 basenp setae & 3 & 2 \\
mandibular palp & 6 & 3 \\
P2-P4 enp1 number of inner setae & 0 & 1 \\
Furcal rami & bare of spinules & covered with small spinules \\
\hline
\end{tabular}

Investigations on corresponding type material confirmed that some specimens from the Angola Basin clearly are Mesocletodes robustus, originally described from the Korsfjorden and Raunefjorden in Norway by F.D. Por (1965). Due to ambiguities in character states between the original description and the type material, a redescription using the newly sampled specimens was made. However, the exclusive difference observed between the type material and the specimens from the Angola Basin is the slightly increased length of furcal rami in the specimens from the Angola Basin. This elongation is due to the stronger elongation between setae 
I and VII. Being the only discernible difference, this character state is considered to be intraspecific variability.

\section{Acknowledgements}

The type material of Mesocletodes brevifurca Lang, 1936 was kindly provided by Karin SindemarkKrønestedt from the Swedish Museum of Natural History in Stockholm. The type material of Mesocletodes robustus Por, 1965 was kindly provided by Prof. Dr. Francis Dov Por and Dr. Ariel Chipman from the Hebrew University of Jerusalem in Israel. We are very grateful for the valuable and constructive criticism of two reviewers and for the correction of the English text by a native speaker. KHG obtained financial support for his participation on DIVA 1 by the Deutsche Forschungsgemeinschaft.

\section{References}

Apostolov, A. (1980) Description des deux genres nouveaux de la famille Cletodidae Sars (Copepoda, Harpacticoida) de la Mer Noire. Musei Macedonici Scientiarum Naturalium, 10, 167-174.

Becker, K. H. (1972) Eidonomie und Taxonomie abyssaler Harpacticoidea (Crustacea, Copepoda). MathematischNaturwissenschaftliche Fakultät. Christian-Albrechts-Universität Kiel, Kiel, p. 163.

Bodin, P. (1997) Catalogue of the new marine Harpacticoid Copepods. Bruxelles: Studioedocumenten van het Koninklijk Belgish Institut voor natuurwetenschappen, 304pp.

Boxshall, G. A. \& Halsey, S. (2004) An Introduction to Copepod Diversity. The Ray Society, Andover, p. 2000.

Brady, G. S. (1872) Contributions to the study of the Entomostraca. No. VII. A list of the non-parasitic marine Copepoda of the north-east coast of England. Annals and Magazine of Natural History, 4, 1-17.

Drzycimski, I. (1967) Zwei neue Cletodidae (Copepoda, Harpacticoida) aus dem westnorwegischen Küstengebiet. Sarsia, 29, 199-206.

Fiers, F. (1986) New and interesting copepods (Crustacea, Copepoda) from brackish waters of Laing Island (Northern Papua New Guinea). Bulletin van het Koninklijk Belgisch Instituut voor Natuurwetenschappen, 56, 99-120.

George, K. H. (2004) Description of two new species of Bodinia, a new genus incertae sedis in Argestidae Por, 1986 (Copepoda, Harpacticoida), with reflections on argestid colonization of the Great Meteor Seamount plateau. Organisms, Diversity \& Evolution, 4, 241-264.

George, K.H. (2008) Argestes angolaensis sp. nov. (Copepoda: Harpacticoida: Argestidae) from the Angola Basin (Southeast Atlantic), and the phylogenetic characterization of the taxon Argestes Sars, including the redescription of A. mollis Sars, 1910, and A. reductus (Itô, 1983). Zootaxa, 1866, 223-262.

Giesbrecht, W. (1892) Systematik und Faunistik der pelagischen Copepoden des Golfes von Neapel und der angrenzenden Meeres-Abschnitte. Fauna und Flora des Golfes von Neapel und der angrenzenden MeeresAbschnitte (Vol. 19): Zoologische Station zu Neapel. 831pp.

Hicks, G. R. F. \& Coull, B. C. (1983) The ecology of marine meiobenthic harpacticoid copepods. Oceanography and Marine Biology. An Annual Review, 21, 67-175.

Huys, R. (1996) Superornatiremidae fam. nov. (Copepoda: Harpacticoida): an enigmatic family from North Atlantic anchihaline caves. Scientia Marina, 60, 497-542.

Huys, R. \& Conroy-Dalton, S. (1997) Discovery of hydrothermal vent Tantulocarida on a new genus of Argestidae (Copepoda: Harpacticoida). Cahiers de Biologie Marine, 38, 235-249.

Itô, T. (1983) Harpacticoid copepods from the Pacific abyssal off Mindanao. II. Cerviniidae (cont.), Thalestridae, and Ameiridae. Publications of the Seto Marine Biological Laboratory, 28, 151-254.

Kröncke, I. \& Türkay, M. (2003) Structural and functional aspects of the benthic communities in the deep Angola Basin. Marine Ecology Progress Series, 260, 43-53.

Lang, K. (1936a) Copepoda Harpacticoida. In: S. Bock (Ed), Further results of the Swedish Antarctic Expedition, 1901-1903, Stockholm, pp. 1-68.

Lang, K. (1936b) Die Familie der Cletodidae SARS 1909. Zoologische Jahrbücher (Systematik), 68, 445-588.

Lang, K. (1936c) Die während der schwedischen Expedition nach Spitzbergen 1898 und nach Grönland 1899 eingesammelten Harpacticiden. Kungliga Svenska Vetenskapskademiens Handlingar, 15, 1-55.

Lang, K. (1948) Monographie der Harpacticiden I+II, reprint. Lund: Otto Koeltz Science Publishers, 1682pp.

Lee, W. \& Huys, R. (2000) New Aegisthidae (Copepoda: Harpacticoida) from western Pacific cold seeps and hydrothermal vents. Zoological Journal of the Linnean Society, 129, 1-71. 
Martínez Arbizu, P. \& Schminke, H. K. (2005) DIVA-1 expedition to the deep sea of the Angola Basin in 2000 and DIVA-1 workshop in 2003. Organisms, Diversity \& Evolution, 5, 1-2.

Noodt, W. (1971) Ecology of the copepoda. In: N. C. Hulings (Ed), pp. 97-102.

Noodt, W. (1952) Marine Harpacticiden (Cop.) aus dem eulitoralen Sandstrand der Insel Sylt. Abhandlungen Mathematisch-Naturwissenschaftlichen Klasse Akademie Wissenschaftliche Mainz, 3,105-142.

Pallares, R. E. (1979) Littoral harpacticoid copepods of Tierra del Fuego (Argentina), Isla de los Estados 3. Contribuciones Cientificas del Centro de Investigaciones de Biologia Marina, B. Aires, 142, 1-22.

Por, F. D. (1965) Harpacticoida (crustacea, copepoda) from muddy bottoms near Bergen. Reprinted from Sarsia, 21, $1-16$.

Por, F. D. (1967) Level Bottom Harpacticoida (Crustacea, Copepoda) from Eilat (Red Sea), Part I. Israel Journal of Zoology, 16, 101-165.

Por, F. D. (1979) The Copepoda of Di Zahav pool (Gulf of Elat, Red Sea). Crustaceana, 37, 13-30.

Por, F. D. (1986) New deepsea harpacticoidea (copepoda) of cletodid type, collected in the indian ocean by R/V "Anton Bruun" in 1964. Crustaceana, 50, 78-98.

Rose, A., Seifried, S., Willen, E., George, K. H., Veit-Köhler, G., Bröhldick, K., et al. (2005) A method for comparing within-core alpha diversity values from repeated multicorer samplings, shown for abyssal Harpacticoida (Crustacea: Copepoda) from the Angola Basin. Organisms, Diversity \& Evolution, 5, 3-17.

Sars, G. O. (1909) Copepoda Harpacticoida. Parts XXVII \& XXVIII. Cletodidae (concluded), Anchorabolidae, Cylindropsyllidae, Tachidiidae (part). An Account of the Crustacea of Norway, with short descriptions and figures of all the species, 5, 305-336.

Sars, G. O. (1910) Copepoda Harpacticoida. Parts XXIX-XXX. Tachidiidae (concluded), Metidae, Balaenophilidae, Supplement (part). An Account of the Crustacea of Norway with short descriptions and figures of all the species, 5, 337-368.

Sars, G. O. (1921) Copepoda Supplement. Parts IX \& X. Harpacticoida (concluded), Cyclopoida. An Account of the Crustacea of Norway, with short descriptions and figures of all the species., 7, 1-121.

Schriever, G. (1985) New Harpacticoida from the north Atlantic ocean. VII The description of five new species of the genus Mesocletodes SARS (Cletodidae). Mitteilungen aus dem Zoologischen Museum der Universität Kiel, 2, 1-12.

Scott, T. (1894) On some new and rare Crustacea from Scotland. Annals and Magazine of Natural History, $13,141$.

Scott, T. (1902) VIII. - Notes on gatherings of Crustacea collected by the fishery steamer "Garland" and the steam trawlers "Star of Peace" and "Star of Hope" of Aberdeen, during the year 1901. Fishery Board of Scotland, 20, 447-485.

Scott, T. (1904) On some new and rare crustacea from the scottish seas. 23rd Annual report of the fishery board Scotland, 141-153.

Scott, T. \& A. (1901) On some new Entomostraca collected in the Arctic Seas by W. Bruce. Annals and Magazine of Natural History, 8, 347.

Soyer, J. (1964) Copepodes Harpacticoides de l'étage bathyal de la. region de Banyuls-sur-Mer. V. Cletodidae. T. Scott. Vie et Milieu, 15, 573-643.

Soyer, J. (1966) Copépodes Harpacticoïdes de Banyuls-sur-Mer. 3. Quelques formes du coralligène. Vie et Milieu, 17, 303-344.

Thompson, I. C. (1893) Revised report on the Copepoda of Liverpool Bay. Proceedings and Transactions of the Liverpool Biological Society, 7, 175-230.

Wells, J. B. J. (1985) Keys to aid in the identification of marine harpacticoid copepods. Amendment Bulletin No. 5. Zoology Publications from Victoria University of Wellington, 80, 1-19.

Wells, J. B. J. (2007) An annotated checklist and keys to the species of Copepoda Harpacticoida (Crustacea). Zootaxa, $1568,1-873$.

Willen, E. (2005) A new species of Paranannopus Lang, 1936 (Copepoda, Harpacticoida, Pseudotachidiidae) with atrophic mouthparts from the abyssal of the Angola Basin. Organisms, Diversity \& Evolution, 5, 19-27.

Willey, A. (1935) Harpacticoid Copepoda from Bermuda. Part II. Annals and Magazine of Natural History, 10, 50-100. 